\title{
Estimated U.S. MANUFACTURING PRODUCTION CAPITAL AND TECHNOLOGY BASED ON AN ESTIMATED DYNAMIC ECONOMIC MODEL
}

\author{
BAOLINE CHEN \\ PETER A. ZADROZNY
}

\author{
CESIFO WORKING PAPER NO. 1526 \\ CATEGORY 10: EMPIRICAL AND THEORETICAL METHODS
}

August 2005

An electronic version of the paper may be downloaded

- from the SSRN website: www.SSRN.com

- from the CESifo website:

www.CESifo-group.de 


\title{
Estimated U.S. MANUfacturing PRODUCTION CAPITAL AND TECHNOLOGY BASED ON AN ESTIMATED DYNAMIC ECONOMIC MODEL
}

\begin{abstract}
Production capital and technology, fundamental to understanding output and productivity growth, are unobserved except at disaggregated levels and must be estimated prior to being used in empirical analysis. We develop and apply a new estimation method, based on advances in economics, statistics, and applied mathematics, which involves estimating a structural dynamic economic model of a representative production firm and using the estimated model to compute Kalman-filtered estimates of capital and technology for the sample period. We apply the method to annual data from 1947-97 for U.S. total manufacturing and compare the estimates with those reported by the Bureau of Labor Statistics.
\end{abstract}

JEL Code: C50, C81, D24, L60.

Keywords: Kalman filter estimation of unobserved state variables.

Baoline Chen

Bureau of Economic Analysis

1441 L Street, $N W$

Washington, DC 20230

USA

baoline.chen@bea.gov
Peter A. Zadrozny

Bureau of Labor Statistics

2 Massachusetts Ave., NE

Washington, DC 20212

USA

zadrozny_p@bls.gov

The paper represents the authors' views and does not represent any official positions of the Bureau of Economic Analysis or the Bureau of Labor Statistics. Baoline Chen acknowledges previous financial support from Rutgers University and the Ludwig Boltzmann Institute for Economic Policy Analysis in Vienna, Austria. We thank Michael Binder, Michael Harper, and Randal Verbrugge for comments and William Gullickson, Kurt Kunze, Lawrence Rosenblum, and Ray Wolfe for help in obtaining data. 


\section{Introduction.}

Time series of production capital and total factor productivity (or "technology," as we call the latter here) are fundamental to understanding the processes of output and productivity growth. Unfortunately, capital and technology are unobserved except at the most disaggregated levels of production units and capital components and must be estimated prior to being used in empirical analysis. Standard methods for estimating capital and technology were developed decades ago (Jorgenson, 1963; Solow, 1957) and are based on analytical and computational methods of that era. We develop and apply a new method for estimating production capital and technology, based on advances in economics, dynamic optimization, statistics, and computing over the intervening years.

We apply the method to annual data from 1947-97 for U.S. total manufacturing industries and compare its model-based estimates of capital and technology with standard estimates reported by the Bureau of Labor Statistics (1997). We offer the method and its results as a fresh approach for understanding and estimating capital and technology using modern methods. The four major findings of the application are: (1) The model-based capital estimates are 10 times more uncertain than the model-based technology estimates. (2) The trends of the model-based capital and technology estimates are similar to the trends of standard estimates. (3) The model-based capital and technology estimates imply that above average capital growth in the 1990s - not above average technology growth -- explains above average growth in manufacturing output in the 1990s. (4) Changes in parameter estimates to suit prior views can cause large and unreasonable changes in the model-based capital and technology estimates and, therefore, should be made cautiously.

We are interested in estimating aggregate capital, i.e., at the level of total production capital (equipment and structures) of all manufacturing industries. The present method has two major steps, a model-parameter estimation step followed by an unobserved-variable estimation step. In the first step, we specify and estimate by maximum likelihood a structural dynamic economic model of a representative production firm in an industry. We assume the firm solves a dynamic optimization problem, which is a standard adjustment cost problem except that adjustment costs on capital and technology are derived from a parsimoniously parameterized production function, rather than being stated directly as is usually done. We compute 
and incorporate the resulting optimal decision rules into the two estimation steps. We estimate the model's structural parameters without using any observations on capital or technology. We use only observations on prices and quantities of output, investment, research (short for "research and development"), labor, and materials inputs. We overcome the lack of capital and technology data by using a missing-data variant of the Kalman filter to compute the likelihood function and by using the overidentifying restrictions on reduced-form parameters in terms of structural parameters implied by the optimal decision rules. The reduced-form equations of the estimated model imply correlations between unobserved capital and technology and the observed variables in the model. In the second step, we use these correlations to compute linear least squares estimates (LLSE) of capital and technology, and their standard errors, in terms of the observed variables in the model. The LLSES are implemented using a version of the Kalman filtering algorithm (Anderson and Moore, 1979).

We now review the standard methods for estimating aggregate production capital and technology and, then, discuss the relative advantages of the present estimation method. Aggregate production capital stocks are often estimated using the perpetual inventory equation $(P I E), k_{t}=\delta_{k} k_{t-1}+i_{t}$, where $k_{t}$ is the capital stock being estimated, $i_{t}$ is observed investment flow, and $\delta_{k}$ is one minus a constant capital depreciation rate. Variants of the PIE can accommodate non-constant or non-geometric depreciation (Bureau of Labor Statistics, 1997). Aggregate production capital is also estimated as an index of the service flows of capital components (equipment, structures, and other disaggregates). The component service flows are estimated using Jorgenson's (1963) rental prices and are indexed using expenditure weights. Accordingly, disaggregated data are used in estimating aggregate capital, but, in either case, the estimates depend entirely on investment flows and capital depreciation rates and do not depend on other possible factors such as decision errors (misallocations), which the present method accounts for implicitly. Technology is usually estimated in percentage growth form as the Solow (1957) residual, $\mathrm{d} \tau_{t}=\mathrm{dq}_{\mathrm{t}}-\sum_{\mathrm{i}=1}^{\mathrm{n}} \mathrm{s}_{\mathrm{it}} \mathrm{dx_{it }}$, where $\mathrm{d} \tau$, $\mathrm{dq}$, and $\mathrm{dx}$ it are percentage growth of technology, output, and production inputs, and $\mathrm{s}_{i t}$ are input cost shares.

Generally, the relative advantages of the present method over standard methods are those of an elaborate econometric model over a simple econometric model. The advantages are greater generality (fewer restrictions) and more 
details, hence, more implications. The disadvantages are the need for more and better data, hence, a greater risk of specification error in practice, and greater mathematical and computational complexity. The standard methods for estimating capital and technology, while not in theoretical conflict with each other, are computationally independent. The present method takes the view that capital and technology are jointly determined as the result of purposeful, coordinated, investment and research decisions driven by the same value-maximizing motive. Thus, the model implicitly "disembodies" technology from capital (Jorgenson, 1966b; Hercowitz, 1998). In the standard method, technology is an unexplained residual. Whereas the present method allows for adjustment costs, the standard methods do not. However, the standard methods are nonparametric, except for having to specify capital depreciation, and are much easier to apply.

The present method automatically produces standard errors of the estimates of capital and technology and, therefore, quantifies uncertainty about the estimates. The standard methods have no measures of uncertainty and, therefore, in effect, present their estimates as being certain. We introduce uncertainty by adding disturbances to the PIEs of capital and technology. The disturbances may be viewed as representing subjective uncertainty or exogenous shocks. In practice, most of the uncertainty about capital concerns its depreciation. As the paper shows, adding disturbances to the PIEs has large consequences for the estimates of capital and technology. When the PIE disturbances are excluded, the estimates follow smooth trends, very similar to the standard estimates. When the disturbances are included, the estimates exhibit short-run variations -- random noises and economic cycles - - around their trends and the standard estimates. The economic cycles are transmitted from observed variables through the PIE disturbances.

Recently economists have estimated technology as filtered or smoothed estimates of an unobserved, estimated, exogenous process (Slade, 1989; French, 2000). The present paper goes further by treating capital and technology as joint endogenous processes. We are unaware of other attempts to estimate joint, endogenous, capital and technology processes using filtering or smoothing methods, although these methods have been used to estimate endogenous (rational) inflationary expectations (Burmeister and Wall, 1982; Hamilton, 1985; Zadrozny, 1997). Regression methods have been used to estimate GNP, aggregate capital, and other macroeconomic variables (Romer, 1989; Levy and Chen, 1994; Levy, 2000) but they have more limited applicability and are less efficient. Unlike filtering or smoothing methods, 
regression methods require the estimated variables to be observed in some periods and cannot exploit correlations at all leads and lags. Our approach to modelling capital and technology as joint endogenous processes could be seen as an extension of Lucas (1967), with the benefit of modern analytical and computational methods. Finally, we note Jorgenson, Gollop, and Fraumeni (1987), Adams (1990), Griliches (1995), Caballero (1999), Nadiri and Prucha (1999), and references therein as recent examples of work on production capital and technology.

The paper continues as follows. Section 2 specifies the model and explains how the representative firm's dynamic optimization problem is solved. Section 3 prepares the model for estimation of parameters, capital, and technology by assembling its equations as a vector autoregression (VAR) and, then, restating the VAR as a state representation. Section 3 also discusses the parameter identification and reconstructibility conditions underlying the estimations. Section 4 discusses the application to aggregated U.S. manufacturing data. It discusses sources and properties of the data, statistical and economic properties of the estimated model, and compares the estimates of capital and technology with those published by the Bureau of Labor Statistics. Section 5 contains concluding remarks. Some technical details are in the appendix.

\section{Specification and Solution of the Model.}

Following Zadrozny (1996), we describe an industry in terms of a representative firm (henceforth, "the firm"). Except for scale differences, firm- and industry-level variables are identical. Every period, $t$, the firm maximizes the expected present value of profits,

$$
v_{t}=E_{t} \sum_{k=0}^{\infty} \delta^{k} \pi_{t+k}
$$

with respect to a feedback decision rule, where the maximization is subject to equations to be specified, $E_{t}$ denotes expectation conditional on the firm's information in period $t, \delta \in(\Theta, 1)$ denotes a constant real discount factor, and $\pi_{\mathrm{t}}=\mathrm{r}_{\mathrm{qt}}-\left(\mathrm{c}_{\mathrm{qt}}+\mathrm{c}_{\mathrm{it}}+\mathrm{c}_{\mathrm{rt}}\right)$ denotes real profits equal to revenues minus costs, such that $\mathrm{c}_{\mathrm{qt}}$ is the cost of production and $\mathrm{c}_{\mathrm{it}}$ and $\mathrm{c}_{\mathrm{rt}}$ are direct (nonadjustment) costs of investment in capital and research in technology. Throughout, a real value is a nominal (current dollar) value divided by the GDP 
deflator. The firm's optimization problem is stated precisely at the end of this section.

To obtain a competitive rational-expectations-equilibrium solution, following Lucas and Prescott (1971), we set revenues in $\pi_{\mathrm{t}}$ to the area under the inverse output-demand curve as $r_{q t}=\int_{x=0}^{q t} p_{q}\left(x, d_{t}\right) d x$, where $p_{q}(\cdot)$ is the inverse output-demand curve, $\mathrm{q}_{\mathrm{t}}$ is the production of saleable output, and $\mathrm{d}_{\mathrm{t}}$ is the output-demand state. Alternately, when $r_{q t}=p_{q}\left(q_{t}, d_{t}\right) q_{t}$, the solution represents the monopoly equilibrium.

To obtain linear solution equations, which facilitate estimation and to which the Kalman filter or smoother can be applied, we specify $r_{\mathrm{qt}}, \mathrm{c}_{\mathrm{qt}}, \mathrm{c}_{i t}$, and $\mathrm{c}_{\mathrm{rt}}$ as quadratic forms (constant and linear terms can be ignored). Accordingly, we assume the industry's inverse output-demand curve is

$$
p_{q t}=-\eta q_{t}+d_{t}+\zeta_{p q, t}
$$

where $\eta>0$ is the slope parameter, $d_{t}$ is the demand state generated by the second-order autoregressive $(A R(2))$ process

$$
d_{t}=\phi_{d 1} d_{t-1}+\phi_{d 2} d_{t-2}+\zeta_{d, t},
$$

and $\zeta_{p q, t}$ and $\zeta_{d, t}$ are disturbances. Actually, $\zeta_{p q, t}$ is introduced for purely technical reasons. Its variance is set small enough so that it has no practical effect on the results but large enough so that it numerically stabilizes the Kalman filter. The full set of distributional assumptions on disturbances is stated in section 3 .

To specify $\mathrm{c}_{\mathrm{qt}}$, we first assume that the firm uses capital $(k)$, labor $(\ell)$, and materials $(\mathrm{m})$, to produce saleable output $(q)$, install investment goods (i), and conduct research activities ( $r$ ) (subscript $t$ is omitted sometimes). We assume that the "output activities," $q$, $i$, and $r$, are restricted according to the separable production function

$$
h(q, i, r)=\tau \cdot g(k, l, m),
$$

where $\tau$ is the Hicks-neutral stock of technology. Although $\tau$ is also totalfactor productivity, because $\mathrm{g}(\cdot)$ and $\mathrm{h}(\cdot)$ are indexes of inputs and outputs, we refer to $\tau$ as technology. If $\tau$ were capital augmenting or labor augmenting, 
the production function would be written as $h(q, i, r)=g(\tau k, \ell, m)$ or $h(q, i, r)=$ $\mathrm{g}(\mathrm{k}, \tau \ell, \mathrm{m})$. More specifically, following Kydland and Prescott's (1982) treatment of the utility function, we assume $g(\cdot)$ and $h(\cdot)$ are the constant elasticity functions,

$$
\begin{aligned}
& g(k, \ell, m)=\left(\alpha_{1} k^{\beta}+\alpha_{2} \ell^{\beta}+\alpha_{3} m^{\beta}\right)^{1 / \beta}, \\
& h(q, i, r)=\left(\gamma_{1} q^{\rho}+\gamma_{2} i^{\rho}+\gamma_{3} r^{\rho}\right)^{1 / \rho},
\end{aligned}
$$

where $\alpha_{i}>\odot, \alpha_{1}+\alpha_{2}+\alpha_{3}=1, \beta<1, \gamma_{i}>0, \gamma_{1}+\gamma_{2}+\gamma_{3}=1$, and $\rho>1$. CES $=$ $(\beta-1)^{-1}$ is the constant elasticity of substitution among inputs, and CET = $(\rho-1)^{-1}$ is the constant elasticity of transformation among outputs. Including $i$ and $r$ in $h(\cdot)$ is a parsimonious way of specifying internal adjustment costs. The idea is that positive rates of investment and research use capital, labor, and materials resources, which could otherwise be used to produce more output, and that this trade-off sacrifices ever more output per unit increases in investment and research.

We need the adjustment costs to generate dynamic decision rules for the firm, which determine correlations among current and lagged variables, which are used to estimate unobserved variables in terms of observed variables. Adjustment costs are commonly specified as convex investment costs, which are incurred in addition to purchase costs of investment goods. Here "investment" means investment in production capital and research in technology. In the next step, we derive a quadratic approximation of the dual variable production cost function (DVPCF) from production function (2.4)-(2.5). The DVPCF includes convex, investment and research, adjustment costs. Thus, having already introduced investment and research purchase costs, $p_{i t} i_{t}+p_{r t} r_{t}$, we obtain a conventionally structured specification of investment and research adjustment costs. Although the DVPCF is conventionally structured, it is unconventionally parameterized. We derive the DVPCF from (2.4)-(2.5) to ensure that structural parameters are identifiable. If we had specified a general DVPCF, subject only to symmetry, homogeneity, and curvature restrictions, it would have 28 free parameters, too many for the structural parameters to be identified, hence, estimated. The identification problem arises because 4 of 13 variables in the model are completely unobserved. The missing-data and identification problems are solved by specifying the DVPCF in terms of the 6 free parameters of (2.4)- 
(2.5). For recent reviews of the investment adjustment cost literature, see, for example, Caballero (1999) and Nadiri and Prucha (1999).

Mathematically, convex internal adjustment costs arise in (2.4)-(2.5) when, for given technology, $\tau$, and inputs, $(k, \ell, m)$, the transformation surfaces of the outputs, $(q, i, r)$, are concave to the origin. The adjustment costs are "convex" because the derived DVPCF is convex in $(q, i, r)$. Hall's (1973) analysis shows that the division of the production function into two separate input and output parts, $g(\cdot)$ and $h(\cdot)$, is a necessary condition for the output transformation surfaces to be concave to the origin. Here, $\rho>1$ is a necessary and sufficient condition for the transformation surfaces to be concave. The transformation surfaces become more curved, hence, adjustment costs increase, as $\rho$ increases. Similarly, $\beta<1$ is a necessary and sufficient condition for the input isoquants to be convex to the origin, and the isoquants become more curved, hence, input substitutability decreases, as $\beta$ decreases.

Let $c_{\mathrm{q}}=\mathrm{p}_{\ell} \ell+\mathrm{p}_{\mathrm{m}} \mathrm{m}$, where $\mathrm{p}_{\ell}$ is the real hiring price of labor and $\mathrm{p}_{\mathrm{m}}$ is the real purchase price of materials. Let $c_{i}=p_{i} i$ and $c_{r}=p_{r} r$, where $p_{i}$ and $p_{r}$ are the real purchase prices of investment and research goods and services. Because $\ell$ and $m$ are variable (not subject to adjustment costs) and $k$ and $\tau$ are quasi-fixed (subject to adjustment costs), we refer to $c_{q}$ as the variable cost and to $c_{i}+c_{r}$ as the fixed cost. Let $c_{q}(w)$ denote the dual variable cost function: given $w=\left(w_{1}, \ldots, w_{7}\right)^{\top}=\left(q, i, r, k, \tau, p_{\ell}, p_{m}\right)^{\top}$ (superscript $T$ denotes transposition), $c_{q}(w)=$ minimum of $p_{\ell} \ell+p_{m} m$, with respect to $\ell$ and $m$, subject to production function (2.4)-(2.5).

In the standard approach to multifactor productivity analysis (Bureau of Labor Statistics, 1997), all inputs are treated symmetrically, as variable flows. Accordingly, $c_{q}$ would include all input costs as $c_{q}=p_{k} k+p_{\tau} \tau+p_{\ell} \ell+$ $p_{m} m$, where $p_{k}$ and $p_{\tau}$ are rental prices of capital and technology stocks, obtained using appropriate versions of Jorgenson's (1963) formula for converting investment purchase prices into capital rental prices. Jorgenson's formula is based on more restrictive assumptions, notably that all inputs are variable. In this paper, we instead work with the purchase prices of investment and research because this allows greater flexibility for handling adjustment costs in the firm's dynamic optimization problem. It is the explicit solution of this problem that generates the identifying conditions that allow us to estimate the structural parameters of the model in the face of unobserved capital and technology. 
The constant term in $\pi$ does not affect optimal decisions in the approximate linear-quadratic dynamic optimization problem. Linear terms in $\pi$ contribute only an additional constant term to the optimal decision rule, which is removed by mean adjustment of the data. Therefore, ignoring constant and linear terms, $c_{\mathrm{q}}\left(\mathrm{w}_{\mathrm{t}}\right) \cong(1 / 2) \mathrm{w}_{\mathrm{t}}^{\top} \cdot \nabla^{2} \mathrm{c}_{\mathrm{q}}\left(\mathrm{w}_{\odot}\right) \cdot \mathrm{w}_{\mathrm{t}}$, where $\nabla^{2} \mathrm{c}_{\mathrm{q}}\left(\mathrm{w}_{\odot}\right)$ denotes the Hessian matrix of second partial derivatives of $c_{q}$ evaluated at $w=W_{\ominus} \cdot \nabla^{2} c_{q}\left(W_{\ominus}\right)$ is stated in the appendix, for $w_{\odot}=\left(1,1,1,1,1, \alpha_{2}, \alpha_{3}\right)^{\top}$, a value which results in the simplest expression for $\nabla^{2} c_{q}\left(w_{\odot}\right)$. Therefore,

$$
\pi_{t}=-(1 / 2) \eta q_{t}^{2}+q_{t}\left(d_{t}+\zeta_{p q, t}\right)-(1 / 2) w_{t}^{\top} \cdot \nabla^{2} c_{q}\left(w_{\odot}\right) \cdot w_{t}-p_{i t} i_{t}-p_{r t} r_{t} .
$$

The Hessian matrix, $\nabla^{2} \mathrm{c}_{\mathrm{q}}\left(\mathrm{w}_{\odot}\right)$, is symmetric (henceforth, for simplicity, we often write $\nabla^{2} \mathrm{c}_{\mathrm{q}}\left(\mathrm{w}_{\odot}\right)$ as $\left.\nabla^{2} \mathrm{c}_{\mathrm{q}}\right)$. Ideally, $(1 / 2) \mathrm{w}_{\mathrm{t}}^{\top} \cdot \nabla^{2} \mathrm{c}_{\mathrm{q}}\left(\mathrm{w}_{\odot}\right) \cdot \mathrm{w}_{\mathrm{t}}$ should inherit the following properties from the exact $c_{q}(w)$ function, for all values of $w$ : (i) linear homogeneity in $(q, i, r, k)$; (ii) convexity in $(q, i, r, k)$; (iii) strict convexity in $(q, i, r),(q, i, k),(q, r, k)$, and $(i, r, k)$; (iv) linear homogeneity in $\left(\mathrm{p}_{\ell}, \mathrm{p}_{\mathrm{m}}\right)$; and $(\mathrm{v})$ strict concavity in $\mathrm{p}_{\ell}$ and $\mathrm{p}_{\mathrm{m}}$. In fact, $\mathrm{w}_{\mathrm{t}}^{\top} \cdot \nabla^{2} \mathrm{c}_{\mathrm{q}}\left(\mathrm{w}_{\odot}\right) \cdot \mathrm{w}_{\mathrm{t}}$ satisfies homogeneity restrictions (i) and (iv) for $w=w_{\odot}$ and curvature restrictions (ii), (iii), and (v) for all w.

The difference between $(1 / 2) w_{t}^{\top} \cdot \nabla^{2} c_{q}\left(w_{\odot}\right) \cdot w_{t}$ and the translog cost function (Christensen, Jorgenson, and Lau, 1971, 1973) is that $\nabla^{2} \mathrm{C}_{\mathrm{q}}\left(\mathrm{W}_{\ominus}\right)$ is not stated in logs of variables and that its elements are tightly restricted in terms of the parameters of the model, whereas the translog cost function is stated in logs of variables and its elements are unrestricted except for the homogeneity, convexity, and concavity restrictions. The present model could be specified in logs of variables, but the results would be similar because the data are standardized prior to estimation. As noted above and discussed more below, estimating parameters without any capital and technology data and, then, estimating the unobserved capital and technology requires having sufficient identifying parameter restrictions on the cost function. Although we do not know and would have difficulty determining the full set of identifying costfunction parameterizations, we do know that the general translog cost function is not in this set.

We assume $p_{i}, p_{r}, p_{\ell}$ and $p_{m}$ are exogenous to the industry and are generated by the $A R(2)$ processes 


$$
\begin{aligned}
& \mathrm{p}_{\mathrm{it}}=\phi_{\mathrm{pi}, 1} \mathrm{p}_{\mathrm{i}, \mathrm{t}-1}+\phi_{\mathrm{pi}, 2} \mathrm{p}_{\mathrm{i}, \mathrm{t}-2}+\zeta_{\mathrm{pi}, \mathrm{t}}, \\
& \mathrm{p}_{\mathrm{rt}}=\phi_{\mathrm{pr}, 1} \mathrm{p}_{\mathrm{r}, \mathrm{t}-1}+\phi_{\mathrm{pr}, 2} \mathrm{p}_{\mathrm{r}, \mathrm{t}-2}+\zeta_{\mathrm{pr}, \mathrm{t},} \\
& \mathrm{p}_{\ell \mathrm{t}}=\phi_{\mathrm{p} \ell, 1} \mathrm{p}_{\ell, \mathrm{t}-1}+\phi_{\mathrm{p} \ell, 2} \mathrm{p}_{\ell, \mathrm{t}-2}+\zeta_{\mathrm{p} \ell, \mathrm{t},} \\
& \mathrm{p}_{\mathrm{mt}}=\phi_{\mathrm{pm}, 1} \mathrm{p}_{\mathrm{m}, \mathrm{t}-1}+\phi_{\mathrm{pm}, 2} \mathrm{p}_{\mathrm{m}, \mathrm{t}-2}+\zeta_{\mathrm{pm}, \mathrm{t}},
\end{aligned}
$$

where $\zeta_{\mathrm{pi}, \mathrm{t}}, \zeta_{\mathrm{pr}, \mathrm{t}}, \zeta_{\mathrm{p \ell}, \mathrm{t}}$, and $\zeta_{\mathrm{pm}, \mathrm{t}}$ are disturbances. Processes (2.7) need not be stationary. A constant-coefficient autoregressive process is stationary or asymptotically stable if and only if its characteristic roots are less than one in absolute value. For example, the $p_{i t}$ process is stationary if and only if the roots, $\lambda_{1}$ and $\lambda_{2}$, which solve the characteristic equation, $\lambda^{2}-\phi_{\mathrm{pi}, 1} \lambda-\phi_{\mathrm{pi}, 2}=0$, are less than one in absolute value. The only restriction which we need on processes (2.7) in order to solve the firm's dynamic optimization problem is that $|\bar{\lambda}|<1 / \sqrt{\delta}$, where $|\bar{\lambda}|$ is the largest absolute characteristic root of any equation in processes (2.7).

We assume that capital accumulates according to the continuous-time law of motion

$$
\partial k(s) / \partial s=-f_{k} \cdot k(s)+i(s)+\tilde{\zeta}_{k}(s),
$$

where $f_{k}>0$ is a depreciation parameter and $\tilde{\zeta}_{k}(s)$ is a continuous-time disturbance. Integrating equation (2.8) over the sampling period $s \in[t-1, t)$, on the assumption that $i(s)$ is constant in $[t-1, t)$, we obtain the discrete-time capital law of motion,

$$
\mathrm{k}_{\mathrm{t}}=\phi_{\mathrm{k} 1} \mathrm{k}_{\mathrm{t}-1}+\phi_{\mathrm{i} \Theta} \dot{i}_{\mathrm{t}}+\zeta_{\mathrm{kt}},
$$

where $\phi_{k 1}=\exp \left(-f_{k}\right), \quad \phi_{i 0}=\left[\left(1-\exp \left(-f_{k}\right)\right] / f_{k}\right.$, and $\zeta_{k t}=\int_{s=0}^{1} \exp \left[-f_{k}(1-s)\right] \tilde{\zeta}_{k}(t-$ $1+s) d s$ is the implied discrete-time disturbance. It is customary to specify (2.9) directly, such that $\phi_{i 0} \equiv 1$. However, this specification understates the depreciation of investments undertaken early in a sampling period compared to those undertaken later in the period. The problem could be avoided by treating $\phi_{\mathrm{k} 1}$ and $\phi_{\mathrm{i} \odot}$ as separate parameters, but this specification is less natural and 
introduces an additional parameter. Thus, assuming that $\zeta_{k t} \sim \operatorname{NIID}\left(\odot, \sigma_{k}^{2}\right)$, we parameterize $(2.9)$ in $\phi_{k 1} \in(\odot, 1)$ and $\sigma_{k}^{2}>\odot$, such that $\phi_{i \odot}=\left(\phi_{k 1}-1\right) / \ln \left(\phi_{k 1}\right)$. Similarly, we obtain the discrete-time technology law of motion

$$
\tau_{t}=\phi_{\tau 1} \tau_{t-1}+\phi_{r \Theta} r_{t}+\zeta_{\tau t}
$$

parameterized in $\phi_{\tau 1} \in(\odot, 1)$ and $\sigma_{\tau}^{2}>\odot$, such that $\phi_{\mathrm{r} \Theta}=\left(\phi_{\tau 1}-1\right) / \ln \left(\phi_{\tau 1}\right)$ and $\zeta_{\tau t} \sim$ $\operatorname{NIID}\left(\odot, \sigma_{\tau}^{2}\right)$.

Equations (2.9)-(2.10) imply geometrical depreciation, in which most of capital and technology's depreciation occurs in early periods of their use. A rational-distributed-lag (RDL) specification (Jorgenson, 1966a) could describe more general depreciation patterns, in particular, in which most depreciation occurs in late periods of use. A RDL could also include gestation or time-tobuild lags as additional sources of capital and technology fixity. However, the need for parsimonious parameterization precludes RDL capital and technology equations, at least for the present data. Most RDLs could also be derived from underlying continuous-time specifications (Zadrozny, 1988).

The model's structural components have now been specified. It remains to explain how to solve the firm's dynamic optimization problem and how to assemble specified laws of motion and solved optimal decision rules into a system of linear simultaneous equations that are the equilibrium equations of the model.

To simplify the dynamic optimization problem, we eliminate $\mathrm{q}_{\mathrm{t}}$ by maximizing $\pi_{t}$ with respect to $q_{t}$. Because $q_{t}$ is not a control variable in the laws of motion of $k_{t}$ or $\tau_{t}$, conditional on $i_{t}$ and $r_{t}$ being at their optimal values, the optimal value of $q_{t}$ is given by maximizing $\pi_{t}$ with respect to $q_{t}$. The first-order condition, $\partial \pi_{t} / \partial q_{t}=0$, yields the output supply rule

$$
q_{t}=-\left(c_{11}+\eta\right)^{-1}\left(c_{12} \dot{i}_{t}+c_{13} r_{t}+c_{14} k_{t}+c_{15} \tau_{t}+c_{16} p_{\ell t}+c_{17} p_{m t}-d_{t}\right)+\zeta_{q t},
$$

where $\left(c_{11}, \ldots, c_{17}\right)$ is the first row of $\nabla^{2} c_{q}$ and $\zeta_{q t}$ is an added disturbance.

In addition to adding $\zeta_{\mathrm{pq}, \mathrm{t}}$ to output-demand curve (2.2) and $\zeta_{\mathrm{qt}}$ to output supply rule (2.11), we also add disturbances to labor and materials decision rules (2.12)-(2.13) so that each of the 13 variables in the model has its own disturbance. Although the disturbances are added for purely technical reasons, to ensure that the variables in the model have a nonsingular joint probability 
distribution, as usual, they represent our specification errors or the firm's decision errors, or both.

Similar elimination of $\ell_{t}$ and $m_{t}$ from the dynamic optimization problem is justified because $\ell_{t}$ and $m_{t}$ are not control variables in the laws of motion of $k_{t}$ or $\tau_{t}$. Optimal values of $l_{t}$ and $m_{t}$, conditional on $q_{t}, i_{t}$ and $r_{t}$ being at their optimal values, are recovered using shepard's lemma (a special case of the envelope theorem; Diewert 1971, p. 495),

$$
\begin{aligned}
& \ell_{\mathrm{t}}=\partial \mathrm{c}_{\mathrm{qt}} / \partial \mathrm{p}_{\ell \mathrm{t}}=\mathrm{c}_{61} \mathrm{q}_{\mathrm{t}}+\mathrm{c}_{62} \dot{i}_{\mathrm{t}}+\mathrm{c}_{63} \mathrm{r}_{\mathrm{t}}+\mathrm{c}_{64} \mathrm{k}_{\mathrm{t}}+\mathrm{c}_{65} \tau_{\mathrm{t}}+\mathrm{c}_{66} \mathrm{p}_{\ell \mathrm{t}}+\mathrm{c}_{67} \mathrm{p}_{\mathrm{mt}}+\zeta_{\ell \mathrm{t}}, \\
& \mathrm{m}_{\mathrm{t}}=\partial \mathrm{c}_{\mathrm{qt}} / \partial \mathrm{p}_{\mathrm{mt}}=\mathrm{c}_{71} \mathrm{q}_{\mathrm{t}}+\mathrm{c}_{72} \dot{i}_{\mathrm{t}}+\mathrm{c}_{73} \mathrm{r}_{\mathrm{t}}+\mathrm{c}_{74} \mathrm{k}_{\mathrm{t}}+\mathrm{c}_{75} \tau_{\mathrm{t}}+\mathrm{c}_{76} \mathrm{p}_{\ell \mathrm{t}}+\mathrm{c}_{77} \mathrm{p}_{\mathrm{mt}}+\zeta_{\mathrm{mt}},
\end{aligned}
$$

where $\left(c_{61}, \ldots, c_{67}\right)$ and $\left(c_{71}, \ldots, c_{77}\right)$ are the sixth and seventh rows of $\nabla^{2} c_{q}$, and $\zeta_{\ell t}$ and $\zeta_{m t}$ are added disturbances.

optimality of labor and materials decision rules (2.12) and (2.13) also depends on $\mathrm{c}_{\mathrm{qt}}=(1 / 2) \mathrm{W}_{\mathrm{t}}^{\top} \cdot \nabla^{2} \mathrm{c}_{\mathrm{q}}\left(\mathrm{W}_{\odot}\right) \cdot \mathrm{w}_{\mathrm{t}}$ being a good approximation of production function (2.4)-(2.5). It is easy to derive decision rules for $\ell_{t}$ and $m_{t}$ from the exact cost function implied by (2.4)-(2.5). However, such rules are nonlinear in variables, which complicates parameter estimation and smoothing. Whether exact or approximate rules are used for decisions on $\ell$ and $m$, the approximate linear-quadratic dynamic optimization problem remains unchanged.

To solve the remainder of the firm's dynamic optimization problem, we restate it as a linear optimal regulator problem. We define the $2 \times 1$ control vector $u_{t}=\left(i_{t}, r_{t}\right)^{\top}$ and the $14 \times 1$ state vector $x_{t}=\left(k_{t}, \tau_{t}, p_{i t}, p_{r t}, p_{\ell t}, p_{m t}, d_{t}\right.$,

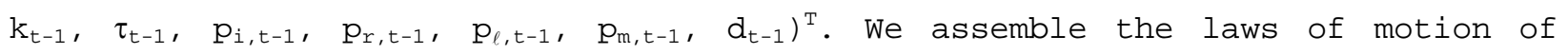
output demand, input prices, capital, and technology, (2.3), (2.7), (2.9), and $(2.10)$, as the state equation

$$
\begin{aligned}
& X_{t}=F X_{t-1}+G u_{t}, \\
& F=\left[\begin{array}{cc}
F_{1} & F_{2} \\
I_{7} & \Theta_{7 \times 7}
\end{array}\right], \quad G=\left[\begin{array}{c}
G_{\odot} \\
\Theta_{12 \times 2}
\end{array}\right],
\end{aligned}
$$

where $F_{1}=\operatorname{diag}\left[\phi_{\mathrm{k} 1}, \phi_{\tau 1}, \phi_{\mathrm{pi}, 1}, \phi_{\mathrm{pr}, 1}, \phi_{\mathrm{p} \ell, 1}, \phi_{\mathrm{pm}, 1}, \phi_{\mathrm{d} 1}\right], \mathrm{F}_{2}=\operatorname{diag}\left[\odot, \odot, \phi_{\mathrm{pi}, 2,} \phi_{\mathrm{pr}, 2}\right.$, $\left.\phi_{\mathrm{p} \ell, 2}, \phi_{\mathrm{pm}, 2}, \phi_{\mathrm{d} 2}\right], \mathrm{G}_{\odot}=\operatorname{diag}\left[\phi_{\mathrm{i} \odot}, \phi_{\tau \odot}\right], \mathrm{I}_{\mathrm{m}}$ is the $\mathrm{m} \times \mathrm{m}$ identity matrix, and $\Theta_{\mathrm{m} \times \mathrm{n}}$ is the $m \times n$ zero matrix. We suppress disturbances in equation (2.14) because the 
regulator problem is certainty equivalent. We use the output-supply rule (2.11) to eliminate $q_{t}$ from $\pi_{t}$ and write $\pi_{t}$ as the quadratic form

$$
\pi_{t}=u_{t}^{\top} R u_{t}+2 u_{t}^{\top} S x_{t-1}+x_{t-1}^{\top} Q x_{t-1} \text {. }
$$

The matrices $R, S$, and $Q$ are stated in the appendix in terms of $\eta$ and the elements of $\nabla^{2} \mathrm{c}_{\mathrm{q}}$.

The regulator problem maximizes expected present value, (2.1), stated in terms of the quadratic form (2.15), with respect to the feedback matrix $\mathrm{K}$ in the linear decision rule $\mathrm{u}_{\mathrm{t}}=\mathrm{K} \mathrm{x}_{\mathrm{t}-1}$, subject to the state equation (2.14). Under concavity, stabilizability, and detectability conditions (Kwakernaak and Sivan, 1972), we compute the optimal K matrix by solving an algebraic matrix Riccati equation using a Schur decomposition method (Laub, 1979). Finally, we write the investment-research decision rule as

$$
\mathrm{u}_{\mathrm{t}}=\mathrm{K} \mathrm{x}_{\mathrm{t}-1}+\left(\zeta_{\mathrm{it}}, \zeta_{\mathrm{rt}}\right)^{\mathrm{T}},
$$

where $\left(\zeta_{i t}, \zeta_{\mathrm{rt}}\right)^{\top}$ is an added $2 \times 1$ disturbance vector.

\section{Estimation Strategy.}

\subsection{State Representation of the Model.}

To estimate the model's parameters by maximum likelihood, using the Kalman filter, and, then, to estimate unobserved capital and technology, also using the Kalman filter, we express the reduced form of the model in a state representation. To this end, we collect the variables of the model in the $13 \times 1$ vector $y_{t}=\left(p_{q t}, q_{t}, \ell_{t}, m_{t}, i_{t}, r_{t}, k_{t}, \tau_{t}, p_{i t}, p_{r t}, p_{\ell t}, p_{m t}, d_{t}\right)^{\top}$ and their disturbances in the $13 \times 1$ vector $\zeta_{\mathrm{t}}=\left(\zeta_{\mathrm{pq}, \mathrm{t}}, \zeta_{\mathrm{qt}}, \zeta_{\mathrm{t} t}, \zeta_{\mathrm{mt}}, \zeta_{\mathrm{it}}, \zeta_{\mathrm{rt}}, \zeta_{\mathrm{kt}}, \zeta_{\mathrm{tt}}, \zeta_{\mathrm{pi}, \mathrm{t}}\right.$, $\left.\zeta_{\mathrm{pr}, \mathrm{t}}, \zeta_{\mathrm{p} \ell, \mathrm{t}}, \zeta_{\mathrm{pm}, \mathrm{t}}, \zeta_{\mathrm{dt}}\right)^{\top}$. We assume that the disturbances are mutually independent, normally distributed, stationary processes, such that the first 6 disturbances are $A R(1)$ processes and the last 7 disturbances are serially independent. That is, we assume $\zeta_{t}=\left(I_{13}-\Theta L\right)^{-1} \varepsilon_{t}$, where $\varepsilon_{t} \sim \operatorname{NIID}\left(\Theta, \Sigma_{\varepsilon}\right), L$ is the lag operator, $\Theta=\operatorname{diag}\left(\theta_{\mathrm{pq}}, \theta_{\mathrm{q}}, \theta_{\ell}, \theta_{\mathrm{m}}, \theta_{\mathrm{i}}, \theta_{\mathrm{r}}, \Theta, \Theta, \Theta, \Theta, \Theta, \Theta, \Theta\right)$, such that the $\theta^{\prime} \mathrm{s} \in$ $(-1,1)$, and $\Sigma_{\varepsilon}=\operatorname{diag}\left(\sigma_{\mathrm{pq}}^{2}, \sigma_{\mathrm{q}}^{2}, \sigma_{\ell}^{2}, \sigma_{\mathrm{m}}^{2}, \sigma_{\mathrm{i}}^{2}, \sigma_{\mathrm{r}}^{2}, \sigma_{\mathrm{k}}^{2}, \sigma_{\tau}^{2}, \sigma_{\mathrm{pi}}^{2}, \sigma_{\mathrm{pr}}^{2}, \sigma_{\mathrm{p} \ell}^{2}, \sigma_{\mathrm{pm}}^{2}, \sigma_{\mathrm{d}}^{2}\right)$. 
The set of equations which form the basis of the parameter and capitaltechnology estimation are (2.2), (2.3), (2.7), (2.9)-(2.13), and (2.16), or more concisely, (2.2), (2.11)-(2.14), and (2.16). These 13 scalar-level equations constitute the complete set of linear simultaneous equations which, for given values of parameters, past variables, and current and past disturbances, determine unique values of the 13 variables of the model. We assemble the equations concisely as

$$
A_{\Theta} y_{t}=A_{1} y_{t-1}+A_{2} y_{t-2}+\left(I_{13}-\Theta L\right)^{-1} \varepsilon_{t},
$$

such that the elements of $A_{\odot}, A_{1}$, and $A_{2}$ are stated in the appendix. We premultiply equation (3.1) by $A_{\odot}^{-1}\left(I_{13}-\Theta L\right)$, such that $A_{\odot}$ is nonsingular for admissible values of parameters. Because the autocorrelation coefficients in $\Theta$ are nonzero only in equations with single lags of variables, the resulting $\operatorname{VAR}(2)$ reduced-form system,

$$
\mathrm{y}_{\mathrm{t}}=\mathrm{B}_{1} \mathrm{y}_{\mathrm{t}-1}+\mathrm{B}_{2} \mathrm{y}_{\mathrm{t}-2}+\xi_{\mathrm{t}}
$$

has only two lags of $y_{t}$, where $B_{1}=A_{\odot}^{-1}\left(A_{1}+\Theta A_{\odot}\right), B_{2}=A_{\odot}^{-1}\left(A_{2}-\Theta A_{1}\right), \xi_{t}=A_{\odot}^{-1} \varepsilon_{t}$ $\sim \operatorname{NIID}\left(\odot, \Sigma_{\xi}\right)$, and $\sum_{\xi} \sim \mathrm{A}_{\odot}^{-1} \sum_{\varepsilon} \mathrm{A}_{\odot}^{-\top}$. Because the input-price equations map unchanged into equation (3.2), they are both structural and reduced-form equations.

A complete state representation comprises a state equation, which expresses the dynamics of the model, and an observation equation, which accounts for how variables in the model are observed. Corresponding to state equation (2.14), we write the reduced-form equation (3.2) as the state equation

$$
\begin{aligned}
& \mathrm{z}_{\mathrm{t}}=\overline{\mathrm{F}} \mathrm{z}_{\mathrm{t}-1}+\overline{\mathrm{G}} \xi_{\mathrm{t},} \\
& \overline{\mathrm{F}}=\left[\begin{array}{cc}
\mathrm{B}_{1} & \mathrm{~B}_{2} \\
\mathrm{I}_{13} & \Theta_{13 \times 13}
\end{array}\right], \quad \overline{\mathrm{G}}=\left[\begin{array}{c}
\mathrm{I}_{13} \\
\Theta_{13 \times 13}
\end{array}\right],
\end{aligned}
$$

where $z_{t}=\left(y_{t}^{\top}, y_{t-1}^{\top}\right)^{\top}$ is the $26 \times 1$ state vector. Associated with the state equation is the observation equation

$$
\bar{y}_{\mathrm{t}}=\overline{\mathrm{H}}_{\mathrm{t}} \mathrm{z}_{\mathrm{t}}
$$


where $\bar{y}_{t}$ is the vector of variables observed in period $t . \bar{H}_{t}$ is called the observation matrix.

Because $\bar{H}_{t}$ is completely flexible in assuming any values in any dimensions, including the null matrix if no observations are available, observation equation (3.4) can account for any pattern of missing data. For most sampling periods in the present application, $\bar{H}_{t}=[\mathrm{J}, 0]$, where $\mathrm{J}=\mathrm{I}_{13}$ with rows of unobserved variables deleted and $\odot$ is the equivalently dimensioned zero matrix. Thus, when variables $4,7,8$, and 13 are unobserved, $J=I_{13}$ with rows $4,7,8$, and 13 deleted and $\odot=\Theta_{9 \times 13}$. Also, $\bar{H}_{t}$ accounts for observations on different observed variables starting and ending in different periods. We call the Kalman filter applied to such a state representation the missing-data Kalman filter.

The missing-data Kalman filter computes the normal distribution (or Gaussian) likelihood function of the observations as follows. Let $\widetilde{y}_{t}=\bar{y}_{t}$ $E\left[\bar{y}_{t} \mid \bar{Y}_{t-1}\right]$ denote the innovation vector, where $\bar{Y}_{t}=\left(\bar{y}_{t}^{\top}, \ldots, \bar{y}_{1}^{\top}\right)^{T}$ denotes the vector of observations through period $t$, and let $\Omega_{t}=E\left[\tilde{y}_{t} \cdot \widetilde{y}_{t}^{\top}\right]$ denote the innovation covariance matrix. In general, the reduced-form disturbance vectors, $\xi_{\mathrm{t}}$, and the innovation vectors, $\tilde{y}_{\mathrm{t}}$, coincide only when all variables are observed throughout the sample. Then, except for terms independent of parameters, -2 times the log-likelihood function of the sample $\bar{Y}_{N}$ is given by

$$
L\left(\vartheta, \bar{Y}_{N}\right)=\sum_{t=1}^{N}\left[\ln \left|\Omega_{t}\right|+\tilde{y}_{t}^{T} \Omega_{t}^{-1} \tilde{y}_{t}\right]
$$

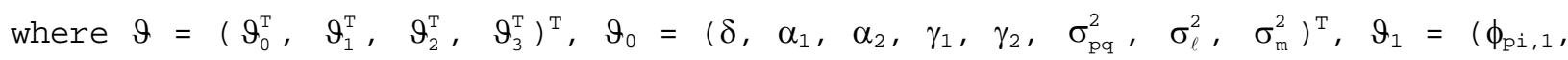

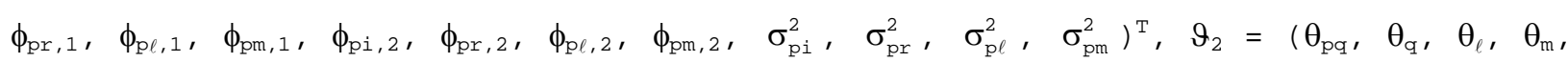
$\left.\theta_{i}, \theta_{r}\right)^{\top}$, and $\vartheta_{3}=\left(\eta, \beta, \rho, \phi_{k 1}, \phi_{\tau 1}, \phi_{d 1}, \phi_{d 2}, \sigma_{q}^{2}, \sigma_{i}^{2}, \sigma_{r}^{2}, \sigma_{k}^{2}, \sigma_{\tau}^{2}, \sigma_{d}^{2}\right)^{\top}$.

As explained further in subsection 3.2, the unidentified 8 parameters in $\vartheta_{\odot}$ are normalized and the remaining 31 parameters in $\vartheta_{1}, \vartheta_{2}$, and $\vartheta_{3}$ are estimated in three steps: $\vartheta_{1}$ in an ordinary-least-squares (OLS) step, $\vartheta_{2}$ in a preliminary maximum-likelihood (ML) step, and $\vartheta_{3}$ in a final ML step. The Kalman filtering recursions for computing (3.5), starting values for the recursions, and other details about implementing the computations accurately and 
efficiently are discussed in Anderson and Moore (1979), Zadrozny (1988, 1990), and references therein. In the $M L$ steps, $L\left(\vartheta, \bar{Y}_{N}\right)$ was minimized using the trust-region method (Mor e' et al., 1980). Although the likelihood could be computed in other ways, the missing-data Kalman-filter method proved to be very effective for handling the various missing-data problems. In particular, in the computer program we needed only to indicate missing values in the data matrix with a missing-data indicator and did not need to transform the reduced-form or state equations, (3.2) or (3.3), as we would using other methods.

\subsection{Parameter Identification and Reconstructibility Conditions.}

The hallmark of the present method is a large number of overidentifying restrictions on the reduced-form parameters, $B_{1}, B_{2}$, and $\Sigma_{\xi}$, in terms of the structural parameters, $\vartheta$, although the structural parameters are unidentified unless additional normalizing restrictions are imposed. Estimation of capital and technology requires that a reconstructibility condition hold. Thus, to estimate the model and use its estimate to estimate capital and technology, the model must satisfy the parameter identification and reconstructibility conditions. We comment no further on the complicated relationship between these conditions, except to note that in our experience parameter identification implies reconstructibility.

The parameter identification condition is standard in econometrics: the unnormalized parameters in $\vartheta$ to be estimated are identified when the Hessian matrix of $L\left(\vartheta, \bar{Y}_{N}\right)$ with respect to them, evaluated at the normalized and estimated values of parameters, is positive definite, i.e., $\nabla^{2} L\left(\hat{\vartheta}_{,} \bar{Y}_{N}\right)>\odot$. The challenge is having enough identifying restrictions on reduced-form parameters in terms of the structural parameters to compensate for the unobservability of some variables. In this case, with $\vartheta_{\odot}$ normalized, the model imposes enough restrictions to identify $\vartheta_{1}, \vartheta_{2}$, and $\vartheta_{3}$. The complexity of the mapping from structural to reduced-form parameters precludes analytically deriving the conditions under which $\vartheta_{1}, \vartheta_{2}$, and $\vartheta_{3}$ are identified. Fortunately, doing this is unnecessary, because after terminating at an estimate, the ML estimation program numerically checks if $\nabla^{2} L\left(\hat{\vartheta}, \bar{Y}_{N}\right)>\odot$.

We estimated the 31 parameters in $\vartheta_{1}, \vartheta_{2}$, and $\vartheta_{3}$ in three steps because initial attempts to estimate them simultaneously resulted in numerical 
breakdown. Although the estimation program converged successfully, it was unable to compute standard errors of the estimated parameters because $\nabla^{2} L\left(\hat{\vartheta}, \bar{Y}_{N}\right)$ was poorly conditioned for inversion. Therefore, we followed the three-step strategy which is consistent but (in theory) inefficient compared to a simultaneous (or full information) estimation strategy. In all three steps, $\vartheta_{\odot}$ is normalized as described below. In step 1, we estimated the 12 input-price process coefficients and disturbance variances in $\vartheta_{1}$ using OLS. In step 2, conditional on $\hat{\vartheta}_{1}$, we estimated the 19 parameters in $\vartheta_{2}$ and $\vartheta_{3}$ using ML. In step 2, $\nabla^{2} L\left(\hat{\vartheta}, \bar{Y}_{N}\right)$ was positive definite but numerically very close to indefiniteness, resulting in very large standard errors of the autocorrelation coefficients in $\hat{\vartheta}_{2}$. Therefore, in step 3 , conditional on $\hat{\vartheta}_{1}$ and $\hat{\vartheta}_{2}$, we reestimated $\vartheta_{3}$ using $\mathrm{ML}$. Thus, the final estimates of $\vartheta$ are $\hat{\vartheta}_{1}$ from step $1, \hat{\vartheta}_{2}$ from step 2, and $\hat{\vartheta}_{3}$ from step 3 .

We imposed normalizing restrictions on $\vartheta_{\odot}$ to ensure that $\vartheta_{1}, \vartheta_{2}$, and $\vartheta_{3}$ are identified. We emphasize that this is normalization, not calibration in the sense of setting parameters so that the model matches selected moments in the data. Being unidentified, the normalized parameters cannot be calibrated in this sense. We verified numerically that the normalized parameters are unidentified by attempting to estimate all structural parameters simultaneously. The estimation algorithm made no moves from given initial parameter values, indicating a flat likelihood function.

We set the discount factor to $\delta=.935$, which corresponds to the interest rate $\delta^{-1}-1=.0695$. We set the weighting parameters in the production function to the "neutral" values $\alpha_{1}=\alpha_{2}=\alpha_{3}=\gamma_{1}=\gamma_{2}=\gamma_{3}=1 / 3$. We considered alternative weighting-parameter normalizations. These resulted in different estimates of $\vartheta_{3}$ but in the same estimates of reduced-form parameters, hence, in the same estimates of capital and technology. We expected that one disturbance variance would have to be restricted for each unobserved variable. Three variables are genuinely unobserved, $k, \tau$, and $d$. To maintain numerical stability of the Kalman filter and smoother, all disturbance variances must be positive. Therefore, we set $\sigma_{\mathrm{pq}}^{2}=\sigma_{\ell}^{2}=\sigma_{\mathrm{m}}^{2} \cong 10^{-10}$. Although setting $\sigma_{\mathrm{pq}}^{2} \cong 0$ is natural, because $\sigma_{\mathrm{pq}}^{2}$ is redundant relative to $\sigma_{\mathrm{d}}^{2}$ in output-demand curve (2.2), setting $\sigma_{\ell}^{2}=\sigma_{\mathrm{m}}^{2} \cong 10^{-10}$ is arbitrary. We could have set these disturbance variances to other values, indeed, could have set any three disturbance 
variances. It makes no difference, because each choice results in the same estimated reduced form. We checked this result by estimating the model under alternative variance normalizations. As described in section 4.1, after some initial estimations, we decided to treat materials quantity, $m$, as unobserved. It would seem, then, that another disturbance variance would have to be moved from $\vartheta_{3}$ to $\vartheta_{\odot}$ and normalized. But this turned out not to be the case. Conditional on $\vartheta_{\odot}$ and $\vartheta_{1}$, under the initial definitions of the $\vartheta^{\prime} s, \vartheta_{2}$ and $\vartheta_{3}$ were still identified. Therefore, we conducted the final estimations using the original normalizations.

To explain reconstructibility, for normally distributed variables, let $\hat{z}_{\mathrm{t} \mid \mathrm{s}}=\mathrm{E}\left[\mathrm{z}_{\mathrm{t}} \mid \overline{\mathrm{Y}}_{\mathrm{s}}\right]$ denote the linear expectation of $\mathrm{z}_{\mathrm{t}}$ conditional on $\overline{\mathrm{Y}}_{\mathrm{s}}$ and let

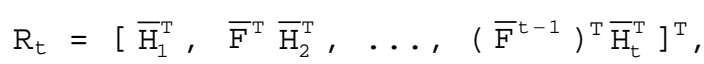

where $\bar{F}$ is the state-transition matrix in (3.3) and $\bar{H}_{t}$ is the observation matrix in (3.4). The state vector, $z_{t}=\left(y_{t}{ }^{\top}, y_{t-1}{ }^{\top}\right)^{\top}$, is said to be reconstructible if there is $a t_{r}$ such that $R_{t}$ has full rank equal to the dimension of $z_{t}$, for $t \geq t_{r}$. Reconstructibility means that, for $t \geq t_{r}$,

$$
\hat{z}_{t \mid t}=\left(R_{t}^{\top} R_{t}\right)^{-1} R_{t}^{\top} \bar{Y}_{t}
$$

where $R_{t}^{\top} R_{t}$ is nonsingular, so that unique filtered estimates of $z_{t}$ (i.e., for $\mathrm{t}|\mathrm{s}=\mathrm{t}| \mathrm{t})$, for $\mathrm{t}=1, \ldots, \mathrm{N}$, can be computed. If (3.7) is feasible, an associated formula computes the error covariance matrix $E\left(z_{t}-\hat{z}_{t \mid t}\right) \cdot\left(z_{t}-\hat{z}_{t \mid t}\right)^{\top}$ in terms of $R_{t}$ and the disturbance covariances. The smoothed estimates of $z_{t}$ (i.e., for $t|s=t| N)$, for $t=1, \ldots, N$, may be expressed similarly. The Kalman smoother is an accurate and efficient recursive algorithm for computing $\hat{z}_{\mathrm{t} \mid \mathrm{N}}$ and $\mathrm{E}\left(\mathrm{z}_{\mathrm{t}}-\hat{\mathrm{z}}_{\mathrm{t} \mid \mathrm{N}}\right) \cdot\left(\mathrm{z}_{\mathrm{t}}-\hat{\mathrm{z}}_{\mathrm{t} \mid \mathrm{N}}\right)^{\top}$, for $\mathrm{t}=1, \ldots, \mathrm{N}$ (Anderson and Moore, 1979).

In the application, the dimension of $z_{t}$ is 26 , so that if $H_{t}$ is time invariant and $z_{t}$ is reconstructible, $t_{r} \leq 26$. This follows from the CayleyHamilton theorem, which says that every square matrix satisfies its own characteristic equation. In such case, for $t \geq 26$, the rows of $\bar{F}^{t}$ are linearly dependent on the rows of $\bar{F}^{25}, \bar{F}^{24}, \ldots, \bar{F}$. Therefore, if $\bar{H}_{t}$ is time invariant, $z_{t}$ is reconstructible if $R_{26}$, called the reconstructibility matrix, 
has full rank 26. It is difficult to determine an upper bound for $t_{r}$ if $\bar{H}_{t}$ is time varying. For a complete discussion of reconstructibility and related concepts, see Kwakernaak and Sivan (1972) or Anderson and Moore (1979). The estimation algorithm numerically checks the reconstructibility condition.

\section{Estimation Results.}

\subsection{Sources and Properties of the Data.}

In estimation, we used annual U.S. total manufacturing data on prices and quantities of output and inputs, from 1947-97. Investment and GDP-deflator data were obtained from the Bureau of Economic Analysis, research data from the National Science Foundation (1998), and all other data from the Bureau of Labor Statistics. All data were obtained in nonseasonal form. All data that were used were previously released to the public and are not confidential. Thus, we obtained observations on 10 of the 13 variables in the model: $p_{\mathrm{qt}}$ and $\mathrm{q}_{\mathrm{t}}$ from 1958-96, $p_{\ell t}$ and $\ell_{t}$ from 1948-97, $p_{i t}$ and $i_{t}$ from 1947-96, $p_{r t}$ and $r_{t}$ from 1953-95, $\mathrm{p}_{\mathrm{mt}}$ from 1958-96, and $\mathrm{m}_{\mathrm{t}}$ from 1958-89.

Except for the quantity of labor, which is measured as the number of production workers, all other prices and quantities were obtained as a nominal price index or a real quantity index coupled with nominal expenditures. We computed the unavailable quantity or price indexes by dividing expenditures by the available price or quantity index, so that in each case the price index $x$ quantity index $=$ nominal expenditures. All obtained or computed nominal price indexes were, then, converted into real form by dividing them by the GDP deflator.

The resulting real prices and quantities of U.S. total manufacturing output and inputs are depicted in figures $1 \mathrm{a}-\mathrm{j}$. For graphing convenience, the data were scaled to lie between $\odot$ and 10. The graphs suggest the following economic interpretation, which is consistent with simulations of the model in figures $2 a-b$. Increasing demand for output driven partly by a declining real price of output induced manufacturers to increase production capacity. Increasing quantities of investment and research built increasing stocks of capital and technology, hence, increased production capacity. As the price of labor increased, manufacturers saved on labor inputs, resulting in flat or declining labor use and increasing labor productivity. 
Figures $1 \mathrm{a}$ to $1 \mathrm{j}$

U.S. Total Manufacturing, Prices and Quantities of Output and Inputs, 1947-97
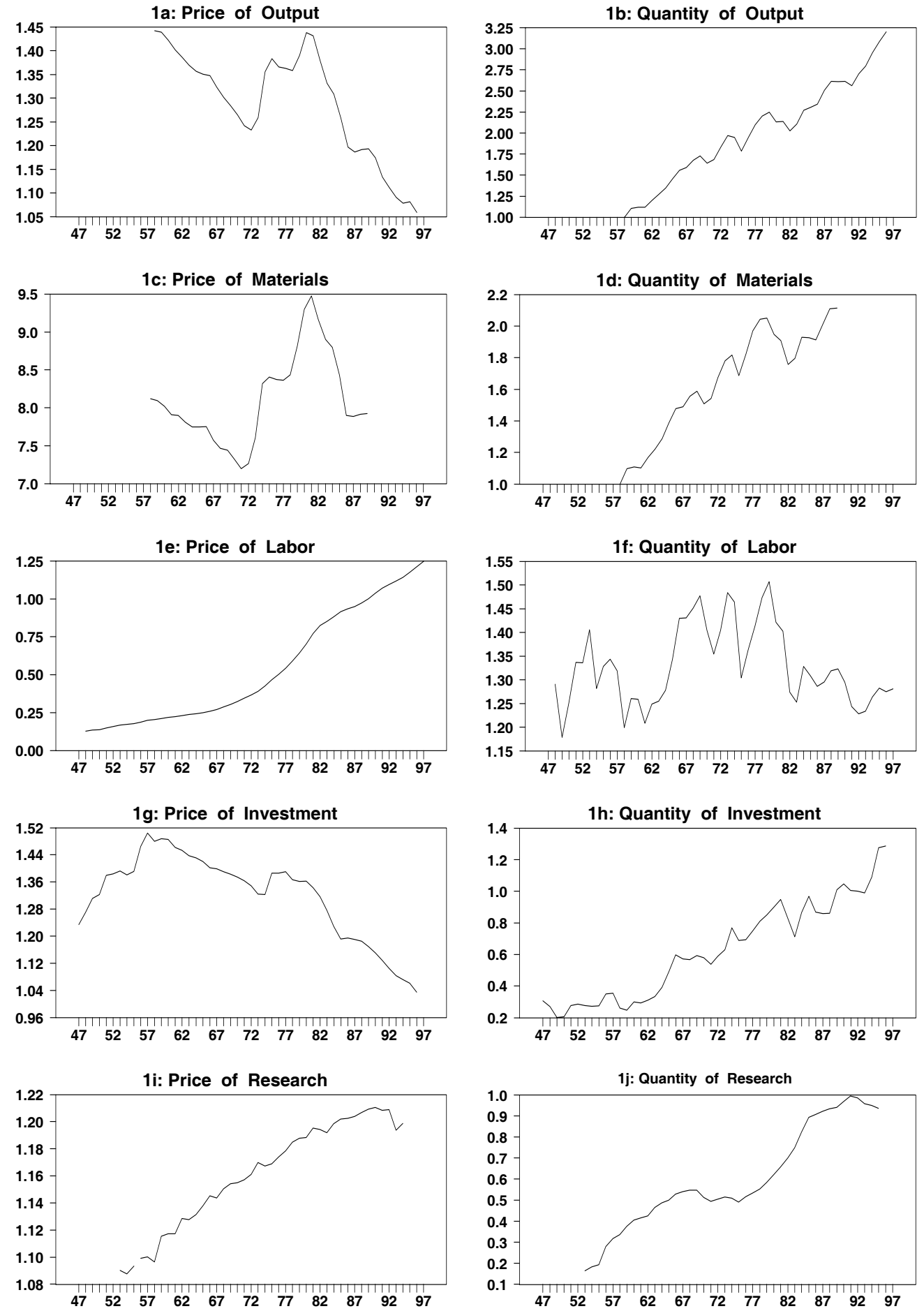
Initially, we considered total hours worked (total production workers multiplied by average hours worked per worker) as an alternate labor input measure. The graph of total hours worked (not shown) is very similar to that of total production workers in figure $1 \mathrm{f}$. The main difference is that total hours worked is a somewhat noisier series. We chose total production workers as the labor input because it resulted in a slightly better fitting, but insignificantly different, estimated model. Choosing total production workers as the labor input caused the $R^{2} s$ of output price and quantity, investment, and research to increase by .01 to .02 and that of labor to increase by .16. Throughout, an $\mathrm{R}^{2}$ refers to the reduced-form equation of a variable.

Initially, we estimated the model using the data described above, but this resulted in a nearly zero $\mathrm{R}^{2}$ for labor. The problem appeared to be misspecification of materials in the production function. The model's simulations and the production function's form indicate symmetrical roles for labor and materials, while the data in figures $1 \mathrm{a}$ and $1 \mathrm{c}$ show the time path of materials matching closely that of output, not that of labor. The solution options were: (i) drop materials price and quantity from the analysis; (ii) assume materials quantity is in fixed proportions to the output good; or (iii) keep materials price and quantity in the model, as they are, continue to use materials price data in the parameter estimation and smoothing, but treat materials quantity as unobserved. Options (i) and (ii) would be implemented implicitly by measuring the output good as value added instead of shipments and dropping materials as a production input. We chose option (iii), which was also the easiest to implement, because it required only that the materials quantity column in the data matrix be filled in with the missing-value indicator. Therefore, in the final round of estimation, materials quantity was treated as unobserved, along with actually unobserved capital, technology, and outputdemand state.

\subsection{Statistical Properties of the Estimated Model.}

Table 1 reports first-step OLS estimates of the input-price process parameters in $\vartheta_{1}$. By conventional standards, the estimated equations fit the data well, having $\mathrm{R}^{2}$ 's greater than .90 . Residuals show no significant autocorrelations, having $p$ values of Ljung-Box $Q$ statistics greater than .25. The estimated $\mathrm{p}_{\mathrm{i}}, \mathrm{p}_{\mathrm{r}}$, and $\mathrm{p}_{\ell}$ processes have characteristic roots near one, with maximum absolute characteristic roots, $|\bar{\lambda}|$, between .785 and 1.02 . A process 
is stationary if and only if its $|\bar{\lambda}|<1$. The complete estimated reduced-form $\operatorname{VAR}(2)$, (3.2), has 5 absolute characteristic roots between .98 and 1.02 for 13 variables. Although a cointegration analysis might seem appropriate, we did not attempt this for two reasons. The input-price processes serve only the subsidiary purpose of providing forecasts for the dynamic optimization problem and their AR(2) specifications are adequate for this task. It is not clear how a standard cointegration analysis, designed for systems in which all variables are observed and coefficients are unrestricted except for unitroot restrictions, applies in this case, in which parameters are restricted by the solution of the dynamic optimization problem and 4 of 13 variables are unobserved. We allowed unit roots insofar as residual autocorrelation coefficients, $\theta$, may be very close to one. Table 2 reports second-step ML estimates of $\hat{\theta}_{\mathrm{pq}}=\hat{\theta}_{\ell}=\hat{\theta}_{\mathrm{m}}=.999$.

Table 1: Step 1 OLS Estimates of Input-Price Process Parameters in $\vartheta_{1}$

\begin{tabular}{|c|c|c|c|c|c|c|}
\hline Var. & \multicolumn{2}{|c|}{ Parameter Estimates } & \multicolumn{3}{|c|}{ Fit Statistics } \\
\hline & $\hat{\phi}_{, 1}$ & $\hat{\phi}_{, 2}$ & $|\bar{\lambda}|$ & $\hat{\sigma}$ & $\mathbf{R}^{2}$ & $\mathbf{Q}$ \\
\hline $\mathbf{p}_{\mathbf{i}}$ & $\begin{array}{c}1.45 \\
(11.1)\end{array}$ & $\begin{array}{c}-.441 \\
(3.30)\end{array}$ & 1.02 & .178 & .971 & $\begin{array}{c}5.64 \\
(.933)\end{array}$ \\
\hline $\mathbf{p}_{\mathbf{r}}$ & $\begin{array}{c}.652 \\
(4.01)\end{array}$ & $\begin{array}{c}.282 \\
(1.81)\end{array}$ & .949 & .126 & .979 & $\begin{array}{c}4.67 \\
(.968)\end{array}$ \\
\hline $\mathbf{p}_{\ell}$ & $\begin{array}{c}1.88 \\
(24.8)\end{array}$ & $\begin{array}{c}-.883 \\
(11.3)\end{array}$ & 1.01 & .019 & .999 & $\begin{array}{c}14.8 \\
(.254)\end{array}$ \\
\hline $\mathbf{p}_{\mathbf{m}}$ & $\begin{array}{c}1.49 \\
(9.79)\end{array}$ & $\begin{array}{c}-.617 \\
(4.06)\end{array}$ & .785 & .334 & .903 & $\begin{array}{c}9.13 \\
(.692)\end{array}$ \\
\hline
\end{tabular}

Comments: Columns 2-7, respectively, show estimates of $\phi_{1,1}$ and $\phi_{, 2}$, with their absolute $t$ statistics in parentheses, implied maximum absolute characteristic roots (solutions of $\lambda^{2}-\hat{\phi}_{, 1} \lambda-\hat{\phi}_{., 2}=0$ ), estimated standard deviations of disturbances, unadjusted $R^{2} s$ (defined as 1 - sample variance of the innovation of a variable $\div$ sample variance of the variable), and LjungBox $Q$ statistics for testing absence of residual autocorrelations at lags from 1 to 10, with their marginal significance levels or $p$ values in parentheses.

Table 2 also reports third-step ML estimates of the remaining parameters in $\vartheta_{3}$. Their absolute $t$ statistics are less than about .5๑ and are not reported 
because the small sample size makes them unreliable and uninformative (Sims, 1980, p. 19, fn. 19). The implied estimated reduced-form equations show unsurprisingly good fits by conventional standards, given that the data are used in original levels form. Moderate $(\cong .50)$ and high $(>.90) \mathrm{R}^{2} \mathrm{~s}$ of labor and the nonlabor variables reflect labor's noisiness and the nonlabor variables' unit-root-like smoothness. The high estimated residual autocorrelation coefficients $(\hat{\theta}$ 's $\geq .84)$ might suggest that the residual autocorrelation corrections and not the economic part of the model account for most of the observed endogenous variables' sample variations, but this is not the case. ML estimation with all $\theta^{\prime}$ 's set to zero produced $R_{p q}^{2}=.918, R_{q}^{2}=$ .879, $\mathrm{R}_{\ell}^{2}=.436, \mathrm{R}_{\mathrm{i}}^{2}=.772$, and $\mathrm{R}_{\mathrm{r}}^{2}=.944$, so that the economic part of the model accounts for these fractions of the endogenous variables' sample variations. Most importantly, as we now discuss in detail, the model's overidentifying restrictions are not rejected by a likelihood ratio test.

Table 2: Step 2 and 3 ML Estimates of Structural Parameters in $\vartheta_{2}$ and $\vartheta_{3}$

\begin{tabular}{|c|}
\hline $\begin{array}{l}\text { Production Function Parameters } \\
\hat{\beta}=-9.14(\text { CES }=-.099), \hat{\rho}=267(\text { CET }=.004)\end{array}$ \\
\hline $\begin{array}{l}\text { Output-Demand Curve Parameters } \\
\hat{\eta}=.605, \hat{\phi}_{\mathrm{d} 1}=1.39, \hat{\phi}_{\mathrm{d} 2}=-.518\end{array}$ \\
\hline $\begin{array}{l}\text { Capital and Technology Equation Coefficients } \\
\hat{\phi}_{\mathrm{k} 1}=.589, \hat{\phi}_{\mathrm{i} \Theta}=.774, \hat{\phi}_{\tau 1}=.161, \hat{\phi}_{\mathrm{r} \Theta}=.459\end{array}$ \\
\hline $\begin{array}{l}\text { Residual Autocorrelation Coefficients } \\
\hat{\theta}_{\mathrm{pq}}=.999, \hat{\theta}_{\mathrm{q}}=.914, \hat{\theta}_{\ell}=.999, \hat{\theta}_{\mathrm{m}}=.999, \hat{\theta}_{\mathrm{i}}=.84 \odot, \hat{\theta}_{\mathrm{r}}=.920\end{array}$ \\
\hline $\begin{array}{l}\text { Structural Disturbance Standard Deviations } \\
\hat{\sigma}_{\mathrm{q}}=.417, \hat{\sigma}_{\mathrm{i}}=.514, \hat{\sigma}_{\mathrm{r}}=.362, \hat{\sigma}_{\mathrm{k}}=.994, \hat{\sigma}_{\tau}=.055, \hat{\sigma}_{\mathrm{d}}=.465\end{array}$ \\
\hline $\begin{array}{c}\text { Reduced-Form Equation Fit Statistics } \\
\mathrm{R}_{\mathrm{pq}}^{2}=.945, \mathrm{R}_{\mathrm{q}}^{2}=.948, \mathrm{R}_{\ell}^{2}=.498, \mathrm{R}_{\mathrm{i}}^{2}=.926, \mathrm{R}_{\mathrm{r}}^{2}=.957 \\
\mathrm{Q}_{\mathrm{pq}}=10.8, \mathrm{Q}_{\mathrm{q}}=5.96, \mathrm{Q}_{\ell}=5.97, \mathrm{Q}_{\mathrm{i}}=18.6, \mathrm{Q}_{\mathrm{r}}=21.4 \\
(.378) \quad(.819) \quad(.818)\end{array}$ \\
\hline
\end{tabular}

Comment: The sample span is 1947-1997 (51 years). $\mathrm{R}^{2}$ and $\mathrm{Q}$ statistics are defined as in table 1.

For large N, abstracting from terms independent of parameters, the maximized log-likelihood function can be expressed as $L\left(\hat{\vartheta}, \bar{Y}_{N}\right)=N \cdot \ln \left|\hat{\Omega}_{N}\right|$, 
where $\hat{\Omega}_{\mathrm{N}}=(1 / \mathrm{N}) \sum_{\mathrm{t}=1}^{N} \tilde{y}_{t} \tilde{y}_{t}^{\top}$. The likelihood-ratio statistic for testing the model's restrictions is $L R=N\left(\ln \left|\hat{\Omega}_{N, R}\right|-\ln \left|\hat{\Omega}_{N, U}\right|\right)$, where $\hat{\Omega}_{N, R}$ and $\hat{\Omega}_{N, U}$ are $\hat{\Omega}_{N}$ based on restricted and unrestricted innovations, i.e., from maximizing the likelihood function with the model's restrictions, respectively, imposed and relaxed. The missing-data Kalman filter automatically produces restricted innovations as part of the ML estimation. We obtained unrestricted innovations as follows. We performed the test using the subsample 1960-1990, because only during this period were observations available for the 9 observed variables. For this period, the observation matrix, $H_{t}$, is time invariant and given by $H=$ $\left[\mathrm{J}, \Theta_{9 \times 13}\right]$, where $\mathrm{J}=\mathrm{I}_{13}$ with rows $4,7,8$, and 13 deleted. Then, combining the state and observation equations, (3.3)-(3.4), we obtain the infinite autoregressive representation for $\bar{y}_{t}$, hence, the finite $p$-lag approximation of this representation,

$$
\bar{y}_{t}=\Phi_{1} \bar{y}_{t-1}+\ldots+\Phi_{p} \bar{y}_{t-p}+\tilde{\tilde{y}}_{t}
$$

where the residual $\tilde{\tilde{y}}_{t}$ is an approximation of the innovation $\tilde{y}_{t}$. We want to test the economic restrictions of the model and not the mutual independence of input-price processes (2.7). Therefore, except for the zero restrictions which make the input-price processes mutually independent, we considered the $\Phi$ 's to be free parameters. For $p=2$, we estimated the individual equations of (4.1) by applying OLS to the period 1960-1990. Thus, we reestimated the input-price processes using the shorter sample. The resulting residuals were serially uncorrelated and were used to compute $\hat{\Omega}_{\mathrm{N}, \mathrm{U}}$.

LR is distributed asymptotically as $\chi^{2}(\kappa)$, in the limit as $N \rightarrow \infty$, where $\kappa$ denotes the number of overidentifying restrictions. The statistic rejects the null hypothesis that the overidentifying restrictions are valid when it exceeds the critical value, $c_{\alpha}$, for the significance level $\alpha$. The period 1960-1990 implies the small values $N=31$ and $N / \kappa=.15$, for $\kappa=118$. For such situations, Sims (1980, p. 17, fn. 18) suggested replacing $N$ with $N-v$ in LR, where, in this case, $v$ is the number of estimated parameters divided by the number of observed endogenous variables. Thus, $N-v=31-(143 / 9)=15.1$ and $\kappa=118$, imply $L R=142$, with a $p$ value of .067, so that the overidentifying restrictions are not rejected at a conventional 5\% significance level. 


\subsection{Economic Properties of the Estimated Model.}

Because the estimates of capital and technology depend critically on the economic model, to be confident in the estimates we should be confident in the economic properties of the model. Therefore, we present and briefly discuss some structural variance decompositions (Sims, 1986) and impulse responses of the estimated model.

We begin by explaining how the variance decompositions are computed. Let $M=I_{13}$ with columns 1,3 , and 4 deleted. Then, combining the state and observation equations, (3.3)-(3.4), we obtain the structural infinite movingaverage representation of $\bar{y}_{t}$, i.e., in terms of the structural disturbance vector, $\varepsilon_{\mathrm{t}}$,

$$
\bar{y}_{t}=\Psi(L) \varepsilon_{t}=\left(\sum_{i=0}^{\infty} \Psi_{i} L^{i}\right) \varepsilon_{t}=\sum_{i=0}^{\infty} \Psi_{i} \varepsilon_{t-i}
$$

where $\Psi_{i}=J\left[\begin{array}{cc}B_{1} & B_{2} \\ I_{13} & \Theta_{13 \times 13}\end{array}\right]^{i}\left[\begin{array}{c}I_{13} \\ \Theta_{13 \times 13}\end{array}\right] M$ and $J$ is defined as in (4.1). M has been introduced to delete the three structural disturbances, $\varepsilon_{\mathrm{pq}, \mathrm{t}}, \varepsilon_{\ell \mathrm{t}}$, and $\varepsilon_{\mathrm{mt}}$, whose variances are normalized to near zero. Let $E\left[\bar{y}_{t+k} \mid \bar{Y}_{t}\right]$ denote the k-stepahead forecast of $\bar{y}_{t+k}$; let $\tilde{y}_{t, k}=\bar{y}_{t+k}-E\left[\bar{y}_{t+k} \mid \bar{Y}_{t}\right]$ denote the forecast error of $E\left[\bar{y}_{t+k} \mid \bar{Y}_{t}\right]$; and, let $V_{k}=E \tilde{y}_{t, k} \tilde{y}_{t, k}^{\top}$ denote the covariance matrix of $\tilde{y}_{t, k}$. Then, $V_{k}$ is given by

$$
V_{k}=\sum_{i=0}^{k} \Psi_{i} \Sigma_{\varepsilon} \Psi_{i}^{\top}
$$

We decompose the k-step-ahead forecast-error variances of the 8 endogenous variables, and their sum, in terms of the 9 unnormalized estimated structural disturbance variances. That is, we decompose $v_{k, i i}$, for $i=1, \ldots$, 8 , and $\sum_{i=1}^{8} v_{k, i i}$, where $v_{k, i i}$ is the $(i, i)$ diagonal element of $v_{k}$, in terms of $\sigma_{j}^{2}$, for $j=2,5,6, \ldots, 13$. Let $s_{k, i, j}$ and $\bar{s}_{k, j}$ denote the fractions of $v_{k, i i}$ and $\sum_{i=1}^{8} v_{k, i i}$ due to $\sigma_{j}^{2}$; let $\Sigma_{\varepsilon}^{1 / 2}$ be the square-root of $\Sigma_{\varepsilon,}$ obtained by replacing the diagonal elements of $\Sigma_{\varepsilon}$ with their positive square roots; let $\mathrm{e}_{i}$ denote the 
$13 \times 1$ vector with one in position $i$ and zeroes elsewhere; and, let $\overline{\mathrm{e}}$ denote the $13 \times 1$ vector with ones in the first 8 positions and zeroes elsewhere. Then, for $i=1, \ldots, 8$ and $j=2,5,6, \ldots, 13$, the percentage variance decompositions of $\mathrm{v}_{\mathrm{k}, \mathrm{ii}}$ and $\sum_{\mathrm{i}=1}^{8} \mathrm{v}_{\mathrm{k}, \mathrm{ii}}$ are given by

$$
\overline{\mathrm{S}}_{\mathrm{k}, \mathrm{j}}=\overline{\mathrm{e}}^{\top}\left(\sum_{\mathrm{i}=\Theta}^{\mathrm{k}} \Psi_{\mathrm{i}} \Sigma_{\varepsilon}^{1 / 2} \mathrm{e}_{\mathrm{j}} \mathrm{e}_{\mathrm{j}}^{\top} \Sigma_{\varepsilon}^{1 / 2} \Psi_{\mathrm{i}}^{\top}\right) \overline{\mathrm{e}} / \overline{\mathrm{e}}^{\top}\left(\sum_{\mathrm{i}=0}^{\mathrm{k}} \Psi_{\mathrm{i}} \Sigma_{\varepsilon} \Psi_{\mathrm{i}}^{\top}\right) \overline{\mathrm{e}}
$$

Table 3: Structural Variance Decomposition of the Estimated Model

\begin{tabular}{|c|c|c|c|c|c|c|c|c|c|c|}
\hline & $\sigma_{\mathrm{q}}^{2}$ & $\sigma_{\mathrm{i}}^{2}$ & $\sigma_{\mathrm{r}}^{2}$ & $\sigma_{\mathrm{k}}^{2}$ & $\sigma_{\tau}^{2}$ & $\sigma_{\mathrm{pi}}^{2}$ & $\sigma_{\mathrm{pr}}^{2}$ & $\sigma_{\mathrm{p} \ell}^{2}$ & $\sigma_{\mathrm{pm}}^{2}$ & $\sigma_{\mathrm{d}}^{2}$ \\
\hline $\mathbf{s}_{10, \mathrm{pq}, \mathrm{j}}$ & 4.5 & 2.8 & .7 & .2 &.$\odot$ & 5.2 & .1 &.$\odot$ & $3 . \odot$ & 83.5 \\
\hline $\mathbf{s}_{10, \mathrm{q}, \mathrm{j}}$ & 19.4 & 12.2 & 3.1 & .8 & .2 & 27.5 & .7 &.$\odot$ & 15.9 & 20.2 \\
\hline $\mathbf{s}_{10, \ell, j}$ & .9 & 3.9 &.$\odot$ & 92.7 & .2 &.$\odot$ &.$\odot$ &.$\odot$ & 1.6 & .1 \\
\hline $\mathbf{s}_{10, \mathrm{~m}, \mathrm{j}}$ & .9 & 3.9 &.$\odot$ & 92.7 & .8 &.$\odot$ &.$\odot$ &.$\odot$ & 1.6 & .1 \\
\hline $\mathbf{s}_{10, \mathrm{i}, \mathrm{j}}$ &.$\odot$ & 44.5 & .1 & 14.3 & .1 & 17.5 & .4 &.$\odot$ & 11.5 & 11.6 \\
\hline $\mathbf{s}_{10, \mathrm{r}, \mathrm{j}}$ &.$\odot$ &.$\odot$ & 5.4 & 1.1 & .2 & 39.3 & $1 . \odot$ & .1 & 25.8 & 27.1 \\
\hline $\mathbf{s}_{10, \mathrm{k}, \mathrm{j}}$ &.$\odot$ & $4 . \odot$ &.$\odot$ & 95.3 &.$\odot$ & .3 &.$\odot$ &.$\odot$ & .2 & .2 \\
\hline $\mathbf{s}_{10, \tau, \mathrm{j}}$ &.$\odot$ &.$\odot$ & 1.9 & 1.1 & 1.6 & 39.9 & 1.1 & .1 & 26.5 & 27.8 \\
\hline$\overline{\mathbf{s}}_{10, \mathrm{j}}$ & 1.3 & 5.2 & .7 & 69.6 & .4 & 7.4 & .2 &.$\odot$ & 5.4 & 9.8 \\
\hline
\end{tabular}

Comment: Rows 2-9 show the percentage decompositions of the 10-step-ahead forecast-error variances of the 8 endogenous variables in terms of the variances of the 10 unnormalized estimated structural disturbances. Row 10 shows the percentage decomposition of the sum of the variances of the eight endogenous variables. Each row's numbers sum to one hundred.

Table 3 shows the structural decompositions of $k=10$ year ahead forecast-error variances. Rows 2-9 show decompositions of variances of endogenous variables; row 10 shows the decomposition of the sum of variances 
of endogenous variables. For example, elements 1, 2, 6, and 10 in row 2 indicate that, according to the estimated model, 4.5, 2.8, 5.2, and 83.5 percent of the variance of $p_{q}$ is, respectively, due to $\sigma_{q}^{2}, \sigma_{i}^{2}, \sigma_{p i}^{2}$ and $\sigma_{d}^{2}$. Because the model is estimated using standardized data, the decompositions are unit free. However, different normalizations of disturbance variances in $\vartheta_{\odot}$ will result in different decompositions. All disturbances, except disturbances of research, technology, price of research, and price of labor, explain significant (> 6\%) fractions of some individual variances or the summed variances. Interestingly, the small impacts of research and technology disturbances run contrary to the real business cycle literature which attributes significant macroeconomic fluctuations to technology shocks. Overall, the decompositions suggest that the capital, output-demand, and investment-price disturbances are the leading sources of variations of the 8 endogenous variables.

\section{Figure 2a: Responses to Impulse in Output-Demand Disturbance}
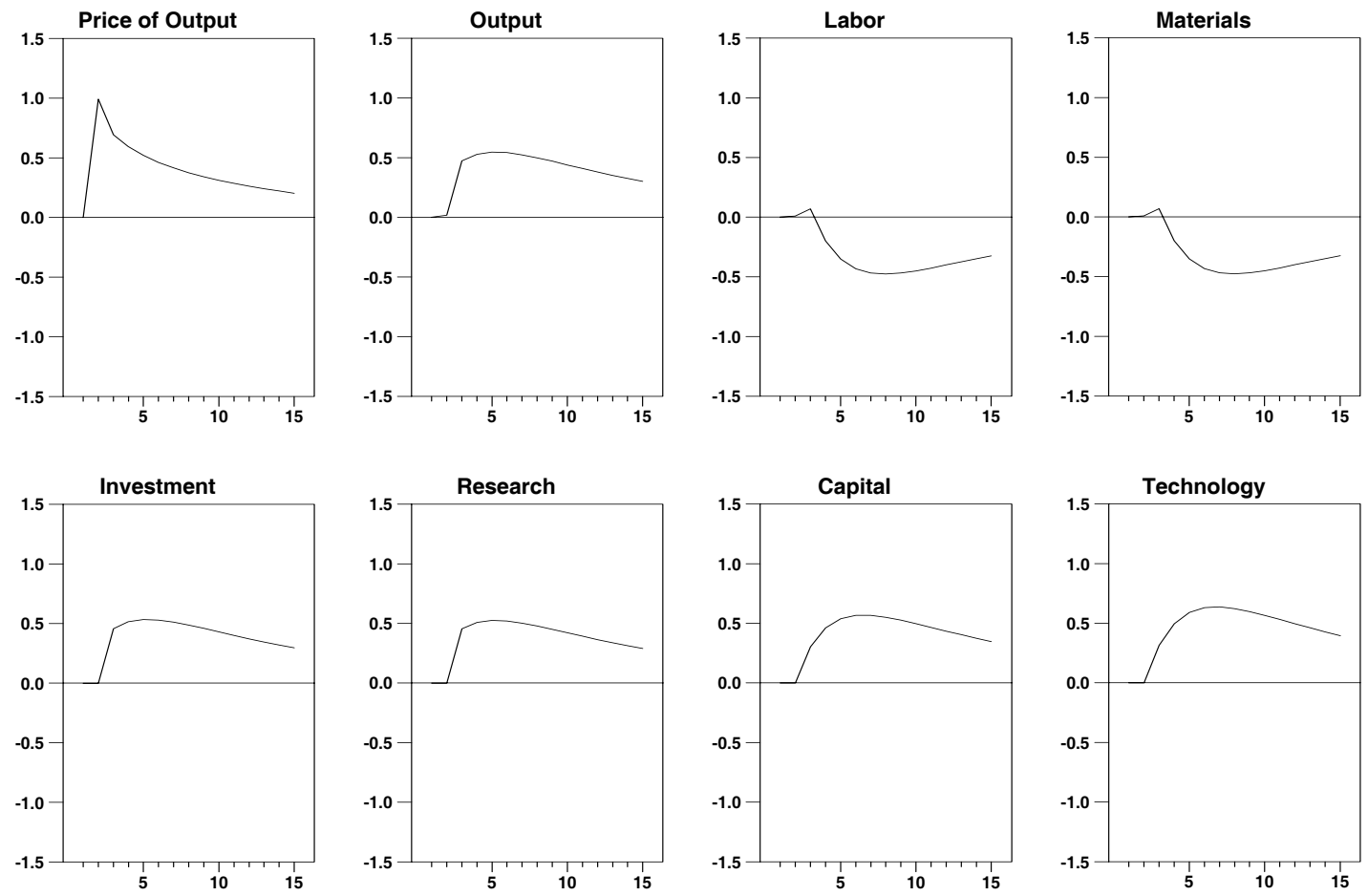


\section{Figure 2b: Responses to Impulse in Technology Disturbance}
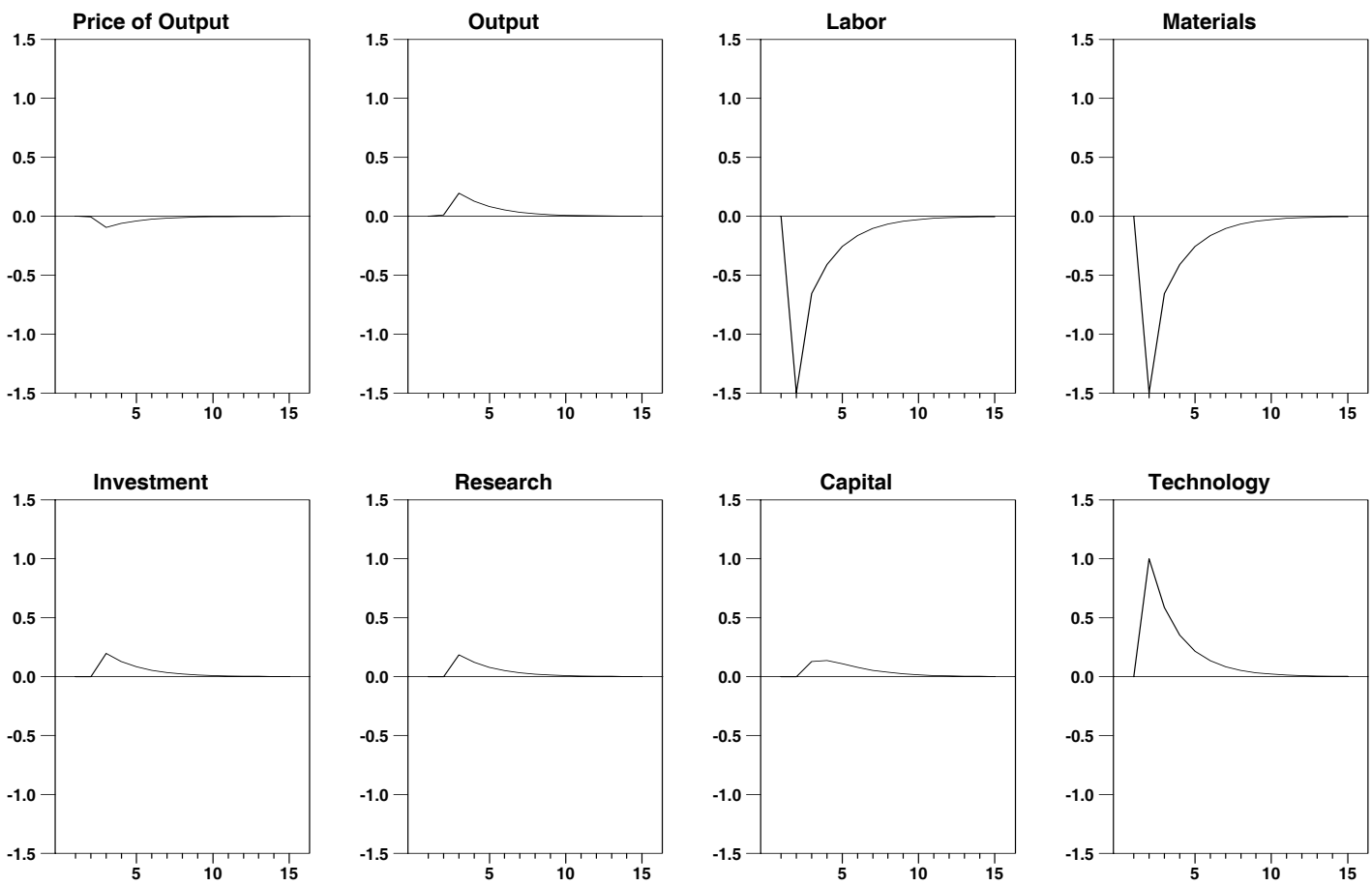

The simulations in figures $2 a-b$ display the dynamic adjustment-cost behavior in the model in response to unit impulses in output-demand and technology disturbances. The simulations in figure $2 a$ match the general interpretation of figures $1 \mathrm{a}-\mathrm{j}$. The simulations depict responses to a unit oneperiod shock (impulse) to the output-demand state in period 1, starting from an initial long-run equilibrium represented by the origin. The estimate $\hat{\eta}=.605$ implies a moderately sloped output-demand curve. The estimates $\hat{\beta}=-9.14$ and $\hat{\rho}$ $=267$ imply CES $=-.099$ and CET $=.004$, hence, low input substitutability and very high adjustment costs on capital and technology. High adjustment costs imply a steep marginal-cost-of-production curve. Therefore, after the outputdemand shock occurs, the price of output rises sharply but output increases only slightly. Initially, the extra output is produced using additional freelyadjusted labor and materials inputs and pre-shock stocks of capital and technology. Because the shocked demand state declines moderately slowly, firms have an incentive to increase their production capacities. Thus, they increase their investment and research rates and substitute capital and technology for labor and materials. Figure $2 \mathrm{~b}$ depicts responses to a unit one-period shock to technology in period 1 , again starting from an initial long-run equilibrium at 
the origin. In figure $2 b$, output-demand conditions remain unchanged so there is little change in price or quantity of output. The shock mainly causes technology to be substituted for labor and materials until the windfall addition to technology has depreciated fully.

\subsection{Model-Based versus Standard Estimates of Capital and Technology.}

By applying the Kalman filter to the estimated model and the data, we compute the filtered state estimates, $\hat{\mathrm{z}}_{\mathrm{t} \mid \mathrm{t}}$, and their error covariance matrices, $E\left(z_{t}-\hat{z}_{t \mid t}\right) \cdot\left(z_{t}-\hat{z}_{t \mid t}\right)^{T}$, for $t=1958, \ldots, 1997$, so that the 7 th and 8th elements of $\hat{z}_{\mathrm{t} \mid \mathrm{t}}$ are the model-based production capital and technology estimates, $\hat{\mathrm{k}}_{\mathrm{t} \mid \mathrm{t}}$ and $\hat{\tau}_{t \mid t}$, and the square roots of the 7 th and 8 th elements of the principal diagonal of the error covariance matrix are the estimated standard errors of $\hat{\mathrm{k}}_{\mathrm{t} \mid \mathrm{t}}$ and $\hat{\tau}_{\mathrm{t} \mid \mathrm{t}}$. Figures $3 \mathrm{a}-\mathrm{b}$ and $4 \mathrm{a}-\mathrm{b}$ display the model-based and standard (production) capital and technology estimates of aggregated U.S. manufacturing industries from 1958-97. The solid graphs depict the model-based estimates and their 2-standard-error confidence intervals. The dashed graphs of capital depict the sum of estimates of the stocks of equipment and structures by the Bureau of Labor Statistics (BLS), based on nonstochastic perpetual inventory equations (PIES). The dashed graphs of technology depict BLS estimates of multifactor productivity computed as Solow residuals. In addition, the BLS estimates the service flows of equipment and structures and the Bureau of Economic Analysis (BEA) estimates the stocks of equipment and structures. Because the BLS capital-service-flow estimates and the BEA capital-stock estimates are sufficiently similar to the BLS capital-stock estimates, the alternative estimates are not displayed or considered further and the BLS capital-stock and multifactor productivity estimates are considered as representative of standard capital and technology estimates.

Because ML estimation of the model is tractable only if all the data are scaled similarly, the data were standardized prior to estimation, by subtracting sample means and dividing by sample standard deviations. Therefore, being based on standardized data, the model-based estimates are in correspondingly standardized units. The BLS estimates are in arbitrarily scaled real units. To compare the two sets of estimates, one set must be converted to the units of the other. Therefore, prior to graphing, we standardized each set of estimates. Also, in each figure, we translated all graphs up by the same amount so that all values are graphed as positive numbers. Because the units of 
the graphs are arbitrary, vertical differences in a graph cannot be interpreted as percentage changes. However, differences between graphs in the same figure are in comparable standardized units. The graphs start in 1958 because output, a critical determinant of the estimates, is first available in 1958.

Figures $3 a-b$ depict graphs of model-based capital and technology estimates based on the parameter estimates in tables 1 and 2. The capital and technology estimates have, respectively, sample average estimated standard errors of 1.03 and .089, which implies that capital's 2-standard-error confidence intervals are over 10 times larger than technology's. Suppose "short-run" means variations with average periodicities of less than about 8 years, which are the sums of unpredictable noises and business cycles, and "long-run" means variations with greater average periodicities, which reflect trends. Then, the model-based capital estimates exhibit frequent and significant short-run variations and the model-based technology estimates exhibit less frequent and less significant short-run variations. Standard filtering or smoothing formulas can decompose the short-run variations into sums of noises, cycles, and trends. However, because the formulas ignore the sampling variability of parameter estimates and model misspecification, the decompositions themselves are uncertain. To the extent that short-run variations reflect cycles, not noises, we can often explain them in terms of identifiable events, such as the Vietnam War (1965-73) and oil-price increases (1973, 1979), and in terms of cyclical fluctuations of the overall economy. The model-based capital and technology estimates exhibit cycles passed from the observed variables through the estimated model. Because they are based on nonstochastic PIEs, the BLS capital estimates exhibit miniscule short-run variations. 
Figures $3 a$ and 3b: Model-Based versus BLS Estimates of Capital and Technology

Figure 3a: Model-Based vs. BLS Estimates of Capital

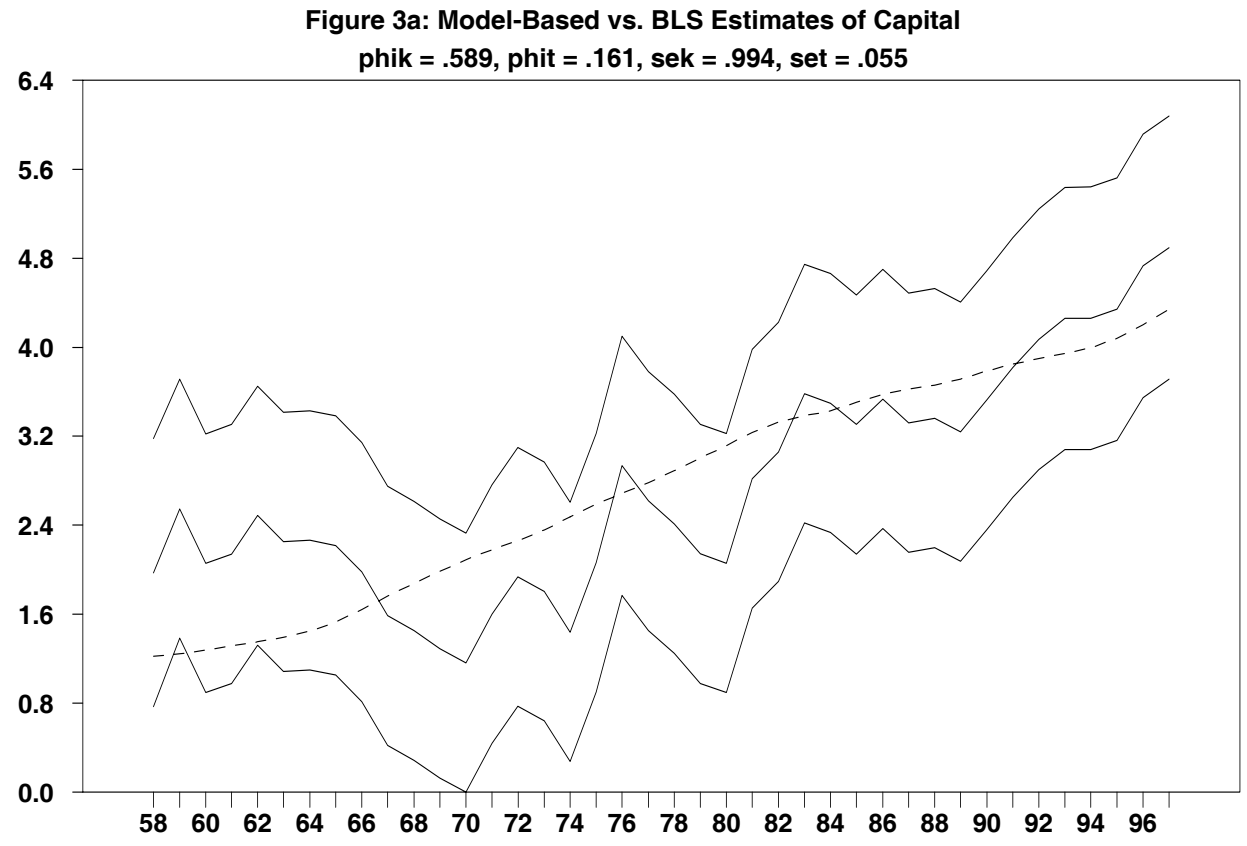

Figure 3b: Model-Based vs. BLS Estimates of Technology

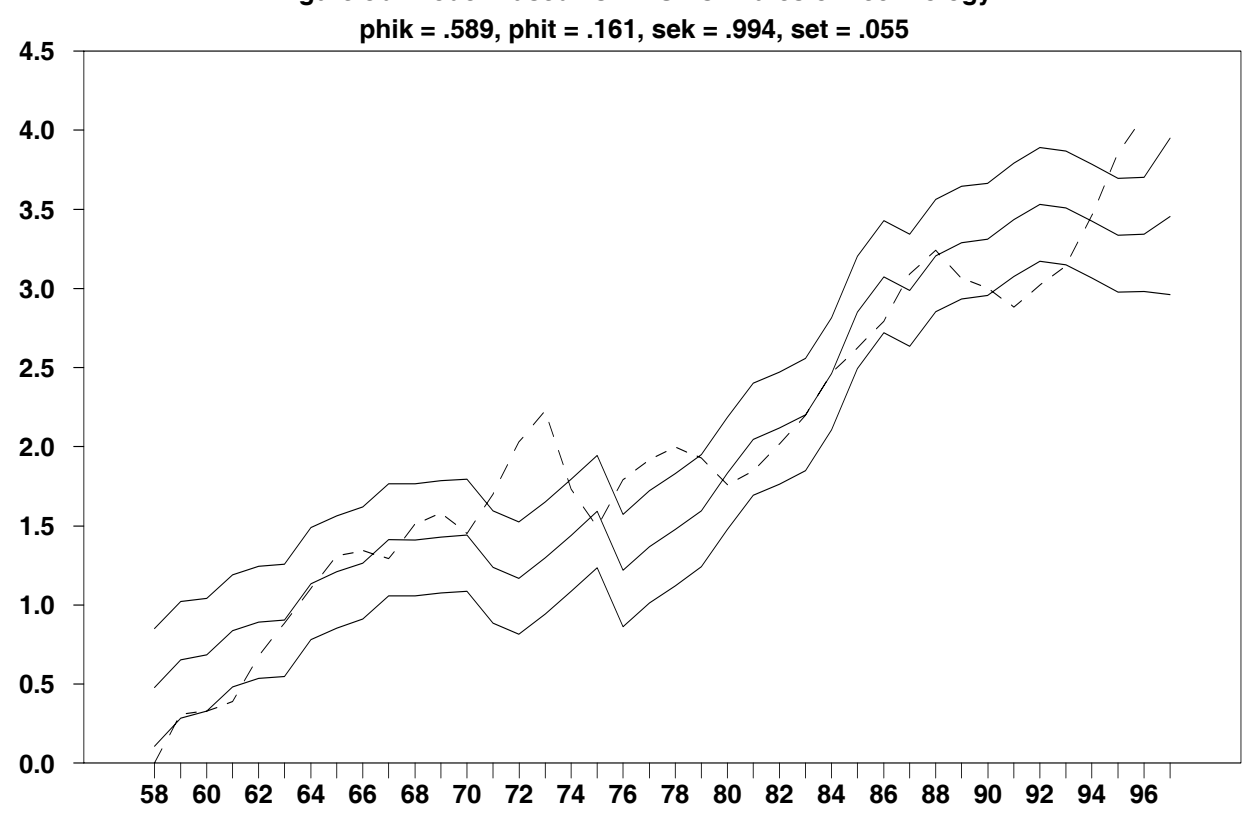


Figures 4a and 4b: Model-Based versus BLS Estimates of Capital and Technology

Figure 4a: Model-Based vs. BLS Estimates of Capital

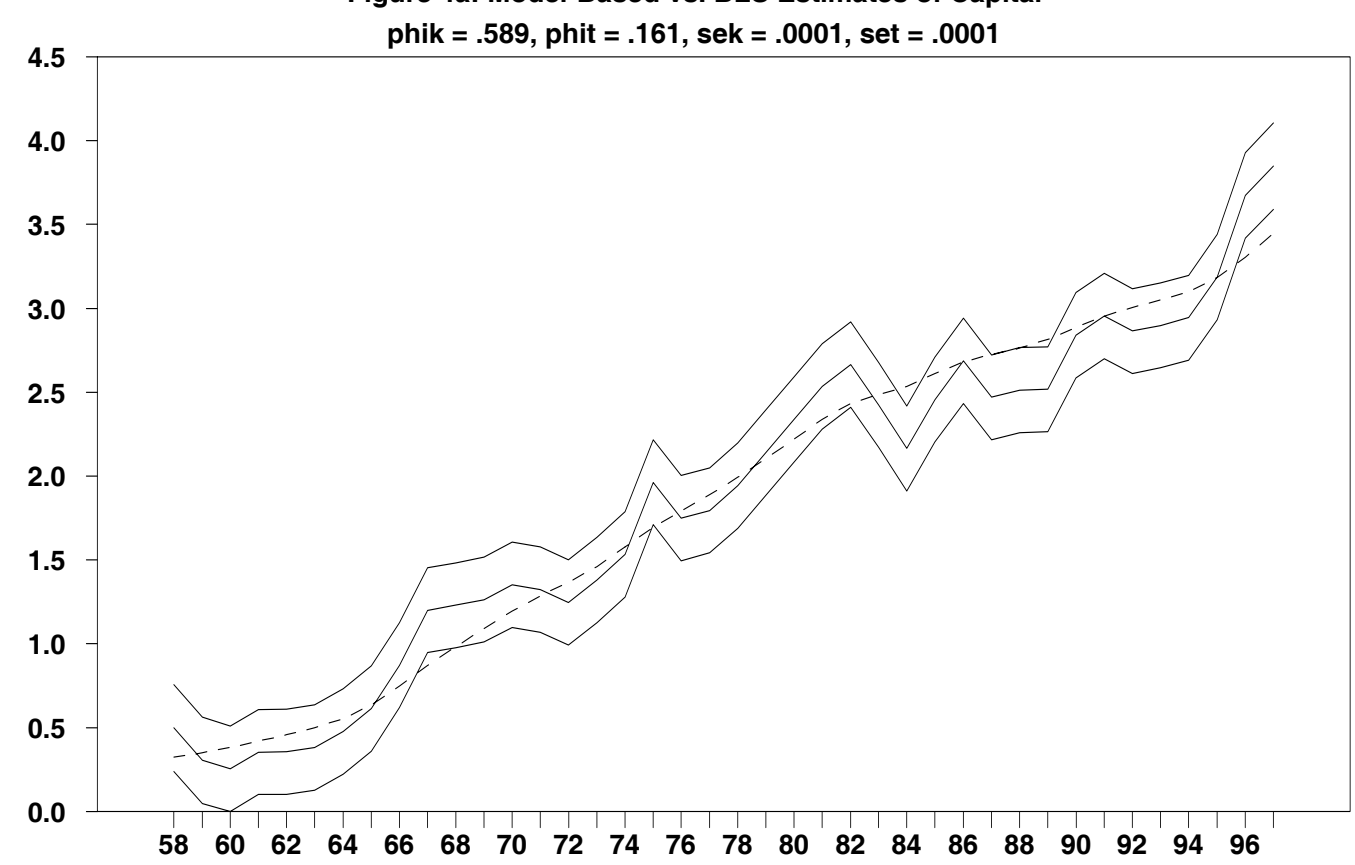

Figure 4b: Model-Based vs. BLS Estimates of Technology phik $=.589$, phit $=.161$, sek $=.0001$, set $=.0001$

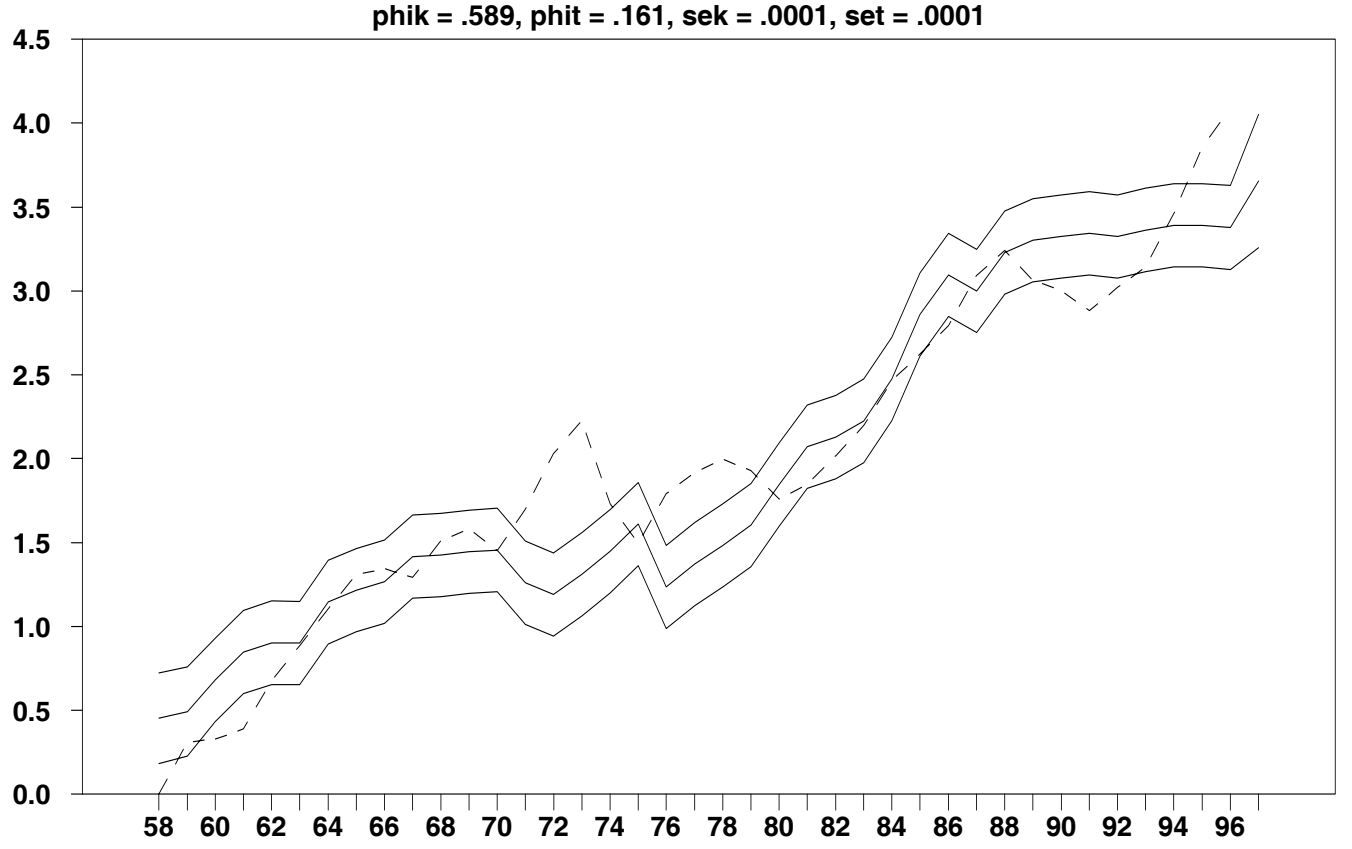


The question arises how the model-based capital and technology estimates change when the estimates of the variances of their disturbances in the PIES are overriden and set to near zero. (The disturbance variances cannot be set exactly to zero because the estimation algorithm collapses unless all structural disturbance variances are least slightly positive.) Thus, figures 4a-b depict alternate model-based capital and technology estimates based on their disturbances set to near zero $\left(\sigma_{\mathrm{k}}^{2}=\sigma_{\tau}^{2}=.0001\right)$, such that all the other structural parameters remain at their estimated values in tables 1 and 2 . Going from figure $3 a$ to $4 a$, the sample average of the estimated standard errors of the model-based capital estimates decline 5-fold, from 1.03 to .205. Setting the capital disturbance variances to near zero does not entirely reduce the capital standard errors to zero because they depend on all structural disturbance variances, but it does reduce them considerably. Thus, going from figure $3 a$ to $4 a$, the short-run variations of the capital estimates also decline 5-fold, causing the estimates to become more trend-like and to conform better to the BLS estimates. Going from figure $3 b$ to $4 b$, causes the sample average of the estimated standard errors of the technology estimates to decline only slightly, from .089 to .060, and, correspondingly, the technology estimates to change little.

Being estimates based on PIES, the model-based and BLS capital estimates could be considered available capital stocks. However, apparently large shortrun variations in the model-based estimates in figure $3 a$ might seem to contradict this notion. Aren't available aggregate capital stocks large relative to investment flows and capital disturbances and don't they depreciate slowly, so that their graphs should be very smooth, like the BLS capital estimates in figure $3 a$ ? We could informally interpret short-run variations in the model-based capital estimates as variations in utilized capital stocks or as variations in effective capital stocks, i.e., adjusted for misallocations. Standard estimation methods treat all capital investments as being equally successful, regardless of misallocations, market realizations, and market valuations. Thus, in the standard accounting, an optimally located factory is considered to add the same amount to capital as a mislocated factory built using the same resources. However, in order to formally interpret the shortrun capital variations as utilized or effective capital, we would have to extend the model to include some notion of capacity utilization or market valuation of capital.

Being Solow residuals, the BLS technology estimates in figure $3 b$ exhibit larger short-run variations than the BLS capital estimates, especially during 
the oil price rises in the 1970s. The BLS technology estimates are usually considered to be the residuals of the production function in the analysis. Here, because both capital and technology are unobserved, either of their estimates could be considered residuals, but, because the model-based capital estimates exhibit larger short-run variations, they are more naturally considered residuals. This is also consistent with capital's role as the residual income earning factor. Technology should reflect more smoothly varying knowledge. Because Solow residuals are noisy, they are often smoothed prior to being considered technology estimates (French, 2000). Being constructed as filtered estimates the model-based technology estimates need not be smoothed further and, in fact, in figures $3 b, 4 b$, and $5 b$ are as smooth or smoother than the BLS Solow-residual estimates.

There has been a debate about whether capital growth or technology growth account for above average output growth in the 1990s (Gordon, 2000; Oliner and Sichel, 2000; Stiroh, 2001). Figure 1 h indicates above average growth of investment in the 1990s; figure $1 j$ indicates first brief above trend growth and then decline of research in the 1990s. Figures $3 a-b$ show correspondingly similar growth patterns of model-based capital and technology estimates in the 1990s. Thus, the model-based estimates indicate that above average capital growth accounts for above average manufacturing output growth in the 1990s. By contrast, for the BLS estimates figures $3 a-b$ indicate that above average technology growth accounts for the recent above average manufacturing output growth.

The parameter estimates in tables 1 and 2 seem reasonable, except possibly for the seemingly low annual capital and technology persistence rates of $\hat{\phi}_{\mathrm{k} 1}=.589$ and $\hat{\phi}_{\tau 1}=.161$. By contrast, Jorgenson and Stephenson (1967) reported a quarterly depreciation rate for equipment and structures in U.S. manufacturing industries from 1947-60, which translates to a higher annual capital persistence rate of $\hat{\phi}_{\mathrm{k} 1}=.895$. In figure 5, to guage the effects of higher capital and technology persistence rates on model-based capital and technology estimates, we set both capital and technology persistence rates to the implied Jorgenson-Stephenson annual capital persistence rate, $\hat{\phi}_{\mathrm{k} 1}=\hat{\phi}_{\tau 1}=$ .895, kept the capital and technology disturbance variances at their figure 4 values, and kept all other parameters at their figure 3 values. 
Figures 5a and 5b: Model-Based versus BLS Estimates of Capital and Technology

Figure 5a: Model-Based vs. BLS

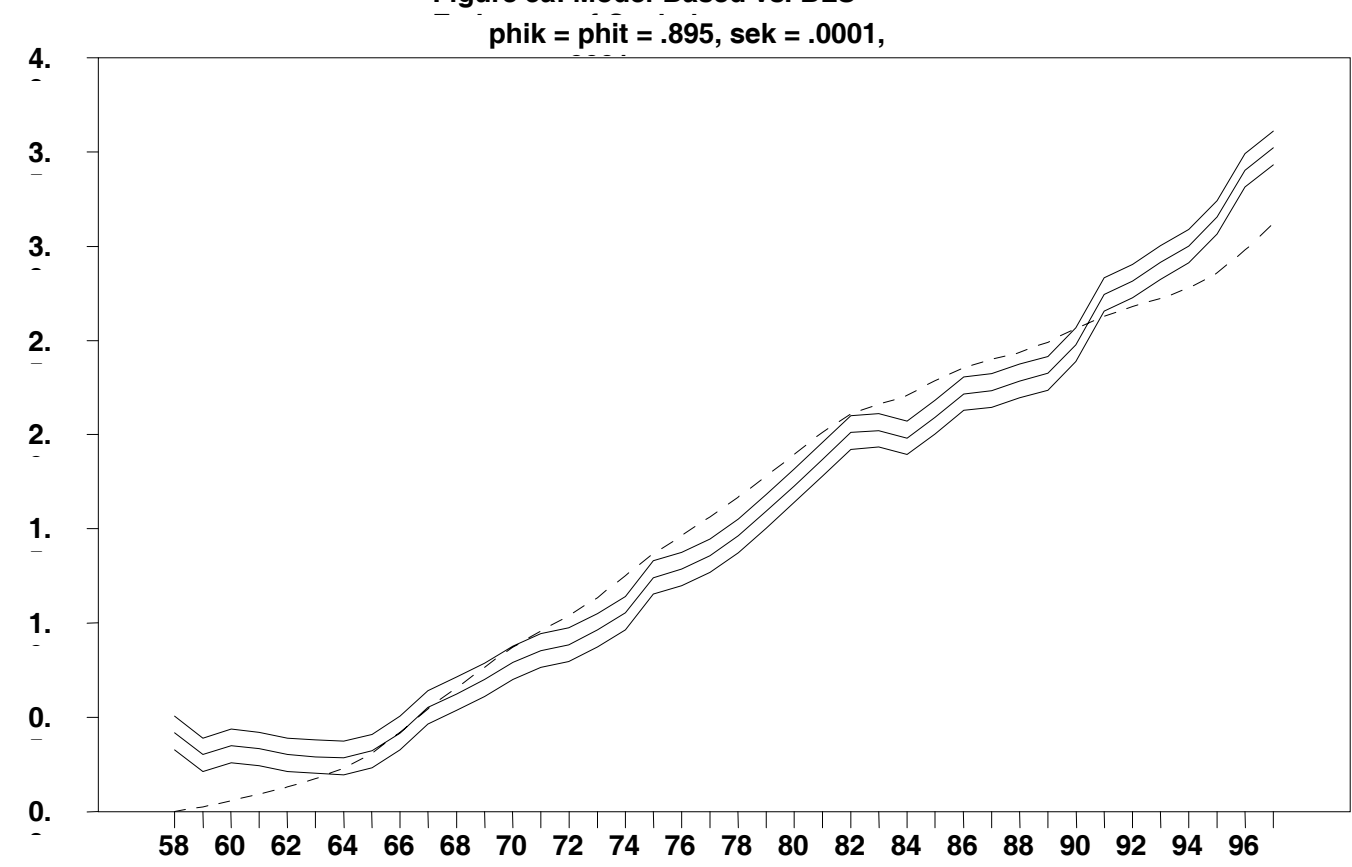

Figure 5b: Model-Based vs. BLS Estimates

4. phik $=$ phit $=.895$, sek $=.0001$,

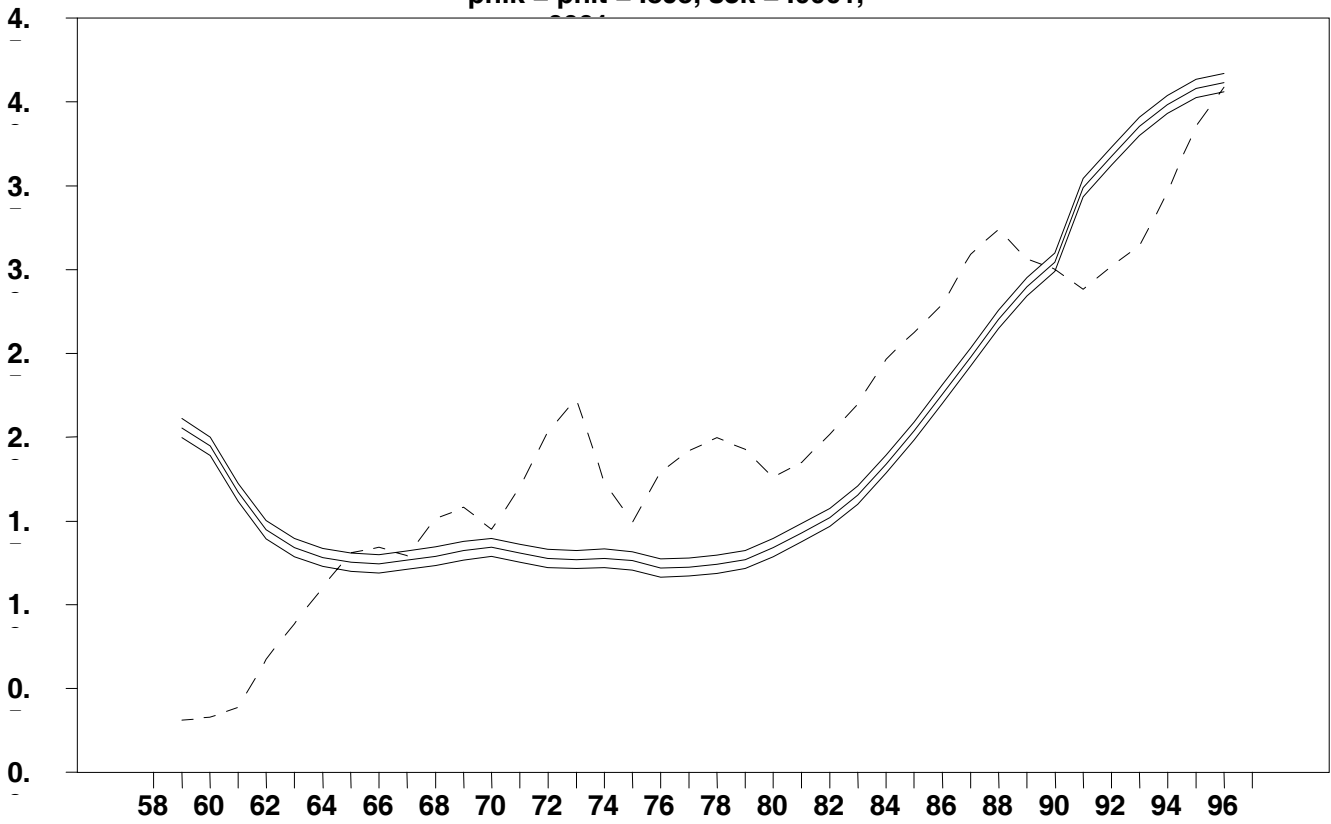


Going from figures $4 \mathrm{a}-\mathrm{b}$ to figures $5 \mathrm{a}-\mathrm{b}$ shows relatively little change in the overall time profiles of the model-based capital and technology estimates, a significant increase in their smoothness, and a corresponding narrowing of their confidence intervals. The exception is the odd initial decline, from 1958 to 1965, in the model-based technology estimate in figure 5b. Although it is unclear why the decline occurs, it tells us that we should be cautious about resetting apparently unsatisfactory estimated parameter values to preferred ones. In this case, resetting $\hat{\phi}_{\mathrm{k} 1}=.589$ and $\hat{\phi}_{\tau 1}=.161$ to $\hat{\phi}_{\mathrm{k} 1}=\hat{\phi}_{\tau 1}=.895$, causes the reasonable initial monotonically-increasing technology estimate to become an unreasonable sharp decline. Thus, we accept the model-based capital and technology estimates in figures $3 a-b$ and, even though the capital estimates in figure $3 a$ are very noisy, we conclude that this simply reflects uncertainty about capital's true values.

Table 4: Nonlinear Least-Squares Estimates of Capital and Technology Eqs.

\begin{tabular}{|c|c|c|c|c|}
\hline \multicolumn{5}{|c|}{ Capital Equation } \\
\hline & $\hat{\phi}_{.1}$ & $\hat{\phi}_{.0}$ & \multicolumn{2}{|c|}{$\mathrm{R}^{2}$} \\
\hline Model-Based Data & $\begin{array}{c}\hat{\phi}_{\mathrm{k} 1}=.336 \\
(22.2)\end{array}$ & $\begin{array}{c}\hat{\phi}_{i 0}=.608 \\
(9.14)\end{array}$ & $\mathrm{R}_{\mathrm{k}}^{2}$ & .730 \\
\hline BLS Data & $\begin{array}{c}\hat{\phi}_{\mathrm{k} 1}=.363 \\
(78.1)\end{array}$ & $\begin{array}{c}\hat{\phi}_{i 0}=.629 \\
(29.3)\end{array}$ & $\mathrm{R}_{\mathrm{k}}^{2}$ & .981 \\
\hline \multicolumn{5}{|c|}{ Technology Equation } \\
\hline Model-Based Data & $\begin{array}{c}\hat{\phi}_{\tau 1}=.376 \\
(118 .)\end{array}$ & $\begin{array}{c}\hat{\phi}_{\mathrm{r} \Theta}=.638 \\
(42.2)\end{array}$ & $\mathrm{R}_{\tau}^{2}$ & .992 \\
\hline BLS Data & $\begin{array}{c}\hat{\phi}_{\tau 1}=.323 \\
(50.8)\end{array}$ & $\begin{array}{c}\hat{\phi}_{\mathrm{r} \Theta}=.599 \\
(21.7)\end{array}$ & $\mathrm{R}_{\tau}^{2}$ & .945 \\
\hline
\end{tabular}

Comment: Columns 2-3 show estimates of the $\phi^{\prime} s$, with their absolute $t$ statistics in parentheses. The $\phi$ 's were estimated in terms of their underlying continuous-time parameters, $f_{k}$ and $f_{\tau}$. The standard errors in the $t$ statistics were computed based on linear approximations of the nonlinear mappings from the f's to the $\phi^{\prime} s$. 
As a further check on the reasonableness of the maximum likelihood estimates $\hat{\phi}_{\mathrm{k} 1}=.589$ and $\hat{\phi}_{\tau 1}=.161$, we estimated the capital and technology equations separately using nonlinear least-squares (NLLS). As in the systemwide ML estimation, the equations are parameterized in terms of their underlying continuous-time parameters. We estimated the equations using the initial model-based and BLS, capital and technology, estimates as real data. The results are reported in table 4. Although the NLLS estimates of $\phi_{k 1}$ and $\phi_{\tau 1}$ in table 4 differ from the ML estimates in table 2, the NLLS estimates are very similar for both the model-based data and the BLS data. As expected, the fit of the estimated equations depends on the noisiness of the dependent variable. Thus, the capital equation fits better when using BLS data $\left(R_{k}^{2}=.891\right)$ than when using the model-based data $\left(R_{k}^{2}=.730\right)$, and the reverse is true for the technology equation. In essence, table 4 confirms what we see in figures 3 and 4 , that the trends of the model-based and BLS capital and technology estimates are similar. Although the ML estimates, $\hat{\phi}_{\mathrm{k} 1}=.589$ and $\hat{\phi}_{\tau 1}=.161$, might seem low in terms of prior economic notions, they are acceptable econometrically, because, along with other parameter estimates, they imply an acceptably fitting model, with overidentifying restrictions which are not rejected. Moreover, the ML estimates of $\hat{\phi}_{\mathrm{k} 1}$ and $\hat{\phi}_{\tau 1}$ and of the other parameters, result in model-based capital and technology estimates which broadly conform to the standard capital and technology estimates. In sum, because the estimation of capital and technology is a system-wide estimation, a seemingly reasonable modification of ML estimates of certain parameters to conform better to prior notions can result in unreasonable capital and technology estimates.

\section{Conclusion.}

The paper has developed a new method for estimating unobserved economic variables based on an estimated dynamic economic model and applies it to estimating production capital and technology (total-factor productivity) of aggregated U.S. manufacturing industries from 1958-97. The method illustrates how modern estimation, control, and filtering methods can be applied to a parsimonious dynamic economic model to produce estimates and standard errors of unobserved variables. Standard methods for estimating capital and technology, developed forty years ago, are appealing in their theoretical and computational simplicity, but are unnecessarily restrictive in some respects, 
for example, ignore adjustment costs. The present method admits adjustment costs of capital and technology, but is more complex analytically, econometrically, and computationally. Because the paper shows that the method is feasible, we urge applying it to other models and data sets. The method is feasible when the economic model imposes enough identifying restrictions to compensate for the unobservability of some of the variables.

The four major findings of the application are: (1) The model-based capital estimates are 10 times more uncertain than the model-based technology estimates as measured by estimated standard errors. (2) The trends of the model-based capital and technology estimates are similar to the trends of the standard estimates. (3) The model-based capital and technology estimates imply that above average capital growth in the 1990s -- not above average technology growth -- explains above average growth in manufacturing output in the 1990s. (4) Changes in parameter estimates to suit prior views can cause unexpectedly large and unreasonable changes in the model-based capital and technology estimates and, therefore, should be made cautiously.

Sorting out the competing interpretations of the model-based capital estimates as available, utilized, or effective capital stocks requires formally introducing some notion of capacity utilization or market valuation of capital. The variance decompositions in table 3 assign principal explanatory roles to capital and investment-price disturbances, which suggests modelling investment and research decisions in more detail. For example, the discount rate might be time-varying, as $\delta_{t}=1 /\left(1+n_{t}\right)$, where $n_{t}$ is an observed exogenous interest rate whose generating process is also estimated. Also, the capital and technology equations might be specified more generally as rational distributed lags, which might include time-to-built gestation lags or non-geometrical depreciation rates of capital and technology.

\section{Appendix: Statement of Cost, Profit, and Reduced-Form Parameters.}

Because $\nabla^{2} \mathrm{C}_{\mathrm{q}}\left(\mathrm{W}_{\odot}\right)$ is symmetric, it suffices to state its upper triangular part. Let $c_{i j}$ denote element $(i, j)$ of $\nabla^{2} c_{q}\left(w_{\odot}\right)$. Then, for $w_{\odot}=(1,1,1,1,1$, $\left.\alpha_{2}, \alpha_{4}\right)^{\top}$, we have:

$$
\begin{array}{ll}
\mathrm{c}_{11}=\gamma_{1}\left(1-\gamma_{1}\right)(\rho-1)+\gamma_{1}^{2} \alpha_{1}(1-\beta) /\left(1-\alpha_{1}\right) & \mathrm{c}_{13}=-\gamma_{1} \gamma_{3}\left[\rho-1+\alpha_{1}(1-\beta) /\left(1-\alpha_{1}\right)\right] \\
\mathrm{c}_{12}=-\gamma_{1} \gamma_{2}\left[\rho-1+\alpha_{1}(1-\beta) /\left(1-\alpha_{1}\right)\right] & \mathrm{c}_{14}=-\gamma_{1} \alpha_{1}(1-\beta) /\left(1-\alpha_{1}\right)
\end{array}
$$




$$
\begin{array}{ll}
\mathrm{c}_{15}=-\gamma_{1}\left(1-\alpha_{1} \beta\right) /\left(1-\alpha_{1}\right) & \mathrm{c}_{36}=\gamma_{3} /\left(1-\alpha_{1}\right) \\
\mathrm{c}_{16}=\gamma_{1} /\left(1-\alpha_{1}\right) & \mathrm{c}_{37}=\gamma_{3} /\left(1-\alpha_{1}\right) \\
\mathrm{c}_{17}=\gamma_{1} /\left(1-\alpha_{1}\right) & \mathrm{c}_{44}=\alpha_{1}(1-\beta)\left[1+\alpha_{1}\left(2-\alpha_{1}\right) /\left(1-\alpha_{1}\right)\right] \\
\mathrm{c}_{22}=\gamma_{2}\left(1-\gamma_{2}\right)(\rho-1)+\gamma_{2}^{2} \alpha_{1}(1-\beta) /\left(1-\alpha_{1}\right) & \mathrm{c}_{45}=-\alpha_{1}+\alpha_{1}\left(2-\alpha_{1}-\beta\right) /\left(1-\alpha_{1}\right) \\
\mathrm{c}_{23}=-\gamma_{2} \gamma_{3}\left[\rho-1+\alpha_{1}(1-\beta) /\left(1-\alpha_{1}\right)\right] & \mathrm{c}_{46}=-\alpha_{1} /\left(1-\alpha_{1}\right) \\
\mathrm{c}_{24}=-\gamma_{2} \alpha_{1}(1-\beta) /\left(1-\alpha_{1}\right) & \mathrm{c}_{47}=-\alpha_{1} /\left(1-\alpha_{1}\right) \\
\mathrm{c}_{25}=-\gamma_{2}\left(1-\alpha_{1} \beta\right) /\left(1-\alpha_{1}\right) & \mathrm{c}_{55}=\left(2-\alpha_{1}-\alpha_{1} \beta\right) /\left(1-\alpha_{1}\right) \\
\mathrm{c}_{26}=\gamma_{2} /\left(1-\alpha_{1}\right) & \mathrm{c}_{56}=-1 /\left(1-\alpha_{1}\right) \\
\mathrm{c}_{27}=\gamma_{2} /\left(1-\alpha_{1}\right) & \mathrm{c}_{57}=-1 /\left(1-\alpha_{1}\right) \\
\mathrm{c}_{33}=\gamma_{3}\left(1-\gamma_{3}\right)(\rho-1)+\gamma_{3}^{2} \alpha_{1}(1-\beta) /\left(1-\alpha_{1}\right) & \mathrm{c}_{66}=-\alpha_{3} /\left[\alpha_{2}\left(1-\alpha_{1}\right)(1-\beta)\right] \\
\mathrm{c}_{34}=-\gamma_{3} \alpha_{1}(1-\beta) /\left(1-\alpha_{1}\right) & \mathrm{c}_{77}=-\alpha_{2} /\left[\alpha_{3}\left(1-\alpha_{1}\right)(1-\beta)\right] . \\
\mathrm{c}_{35}=-\gamma_{3}\left(1-\alpha_{1} \beta\right) /\left(1-\alpha_{1}\right) &
\end{array}
$$

Next, we state the elements of the $2 \times 2,2 \times 14$, and $14 \times 14$ coefficient matrices $R, S$, and $Q$, which define quadratic form (2.15). Because $R$ and $Q$ are symmetric, we state only their upper-triangular parts. $R_{i j}, S_{i j}$, and $Q_{i j}$ denote $(i, j)$ elements of the matrices. To eliminate the common factor $1 / 2$, we scale $\pi_{t}$ up by the factor of 2 , which is allowable because optimal decisions are invariant to the scale of $\pi_{t}$. For simplicity, we state only nonzero elements of $\mathrm{R}$, $\mathrm{S}$, and $\mathrm{Q}$, so that all unstated elements are zero. Thus, setting $\mathrm{c}_{\odot}=$ $\left(\eta+c_{11}\right)^{-1}$, we have

$$
\begin{aligned}
& \mathrm{R}_{11}=\mathrm{C}_{\Theta} \mathrm{C}_{12}-\mathrm{C}_{22} \quad \mathrm{~S}_{16}=\mathrm{C}_{\ominus} \mathrm{C}_{12} \mathrm{C}_{17}-\mathrm{C}_{27} \quad \mathrm{~S}_{27}=-\mathrm{C}_{\ominus} \mathrm{C}_{13} \\
& \mathrm{R}_{12}=\mathrm{C}_{\Theta} \mathrm{C}_{12} \mathrm{C}_{13}-\mathrm{C}_{23} \quad \mathrm{~S}_{17}=-\mathrm{C}_{\Theta} \mathrm{C}_{12} \quad \mathrm{Q}_{11}=\mathrm{C}_{\Theta} \mathrm{C}_{14}^{2}-\mathrm{C}_{44} \\
& \mathrm{R}_{22}=\mathrm{C}_{\odot} \mathrm{C}_{13}^{2}-\mathrm{C}_{33} \quad \mathrm{~S}_{21}=\mathrm{C}_{\ominus} \mathrm{C}_{13} \mathrm{C}_{14}-\mathrm{C}_{34} \quad \mathrm{Q}_{12}=\mathrm{C}_{\Theta} \mathrm{C}_{14} \mathrm{C}_{15}-\mathrm{C}_{45} \\
& \mathrm{~S}_{11}=\mathrm{C}_{\ominus} \mathrm{C}_{12} \mathrm{C}_{14}-\mathrm{C}_{24} \quad \mathrm{~S}_{22}=\mathrm{C}_{\ominus} \mathrm{C}_{13} \mathrm{C}_{15}-\mathrm{C}_{35} \quad \mathrm{Q}_{15}=\mathrm{C}_{\ominus} \mathrm{C}_{14} \mathrm{C}_{16}-\mathrm{C}_{46} \\
& \mathrm{~S}_{12}=\mathrm{C}_{\ominus} \mathrm{C}_{12} \mathrm{C}_{15}-\mathrm{C}_{25} \quad \mathrm{~S}_{24}=-1 \quad \mathrm{Q}_{16}=\mathrm{C}_{\ominus} \mathrm{C}_{14} \mathrm{C}_{17}-\mathrm{C}_{47} \\
& \mathrm{~S}_{13}=-1 \quad \mathrm{~S}_{25}=\mathrm{C}_{0} \mathrm{C}_{13} \mathrm{C}_{16}-\mathrm{C}_{36} \quad \mathrm{Q}_{17}=-\mathrm{C}_{0} \mathrm{C}_{14} \\
& \mathrm{~S}_{15}=\mathrm{C}_{\ominus} \mathrm{C}_{12} \mathrm{C}_{16}-\mathrm{C}_{26} \quad \mathrm{~S}_{26}=\mathrm{C}_{\ominus} \mathrm{C}_{13} \mathrm{C}_{17}-\mathrm{C}_{37}
\end{aligned}
$$


$\begin{array}{ll}\mathrm{Q}_{22}=\mathrm{C}_{\ominus} \mathrm{C}_{15}^{2}-\mathrm{C}_{55} & \mathrm{Q}_{26}=\mathrm{C}_{\ominus} \mathrm{C}_{15} \mathrm{C}_{17}-\mathrm{C}_{57} \\ \mathrm{Q}_{25}=\mathrm{C}_{\ominus} \mathrm{C}_{15} \mathrm{C}_{16}-\mathrm{C}_{56} & \mathrm{Q}_{27}=-\mathrm{C}_{\ominus} \mathrm{C}_{15} .\end{array}$

Finally, we state the structural coefficient matrices $A_{k}$, for $k=0,1$, 2. Let $A_{k, i, j}$ and $K_{i, j}$, respectively, denote elements $(i, j)$ of $A_{k}$ and $K$, the optimal investment-research feedback matrix. As before, only nonzero elements are stated. Also, because the diagonal elements of $A_{\ominus}$ are all one, they are not stated. Proceeding row-wise across the matrices,
$A_{\ominus, 1,2}=\eta$
$A_{\odot, 3,2}=-C_{16}$
$A_{0,4,6}=-C_{37}$
$A_{0,1,13}=-1$
$A_{\ominus, 3,5}=-C_{26}$
$A_{0,4,7}=-C_{47}$
$A_{0,2,5}=C_{0} C_{12}$
$A_{\ominus, 3,6}=-C_{36}$
$A_{\ominus, 4,8}=-C_{57}$
$A_{\odot, 2,6}=C_{\ominus} C_{13}$
$A_{\odot, 3,7}=-C_{46}$
$A_{\ominus, 4,11}=-C_{67}$
$\mathrm{A}_{\Theta, 2,7}=\mathrm{C}_{\Theta} \mathrm{C}_{14}$
$A_{0,3,8}=-C_{56}$
$A_{0,4,12}=-C_{77}$
$A_{\ominus, 2,8}=C_{\ominus} C_{15}$
$A_{\ominus, 3,11}=-C_{66}$
$A_{\Theta, 7,5}=-\phi_{\text {i๑ }}$
$A_{\ominus, 2,11}=C_{\ominus} C_{16}$
$A_{\ominus, 3,12}=-C_{67}$
$\mathrm{A}_{\Theta, 8,6}=-\phi_{\mathrm{r} \Theta}$
$\mathrm{A}_{\ominus, 2,12}=\mathrm{C}_{\ominus} \mathrm{C}_{17}$
$A_{\ominus, 4,2}=-C_{17}$
$A_{\ominus, 2,13}=-C_{\ominus}$
$A_{\ominus, 4,5}=-C_{27}$
$\left[A_{1,5,7}, \ldots, A_{1,5,13}\right]=\left[K_{1,1}, \ldots, K_{1,7}\right]$
$\left[\mathrm{A}_{1,6,7}, \ldots, \mathrm{A}_{1,6,13}\right]=\left[\mathrm{K}_{2,1}, \ldots, \mathrm{K}_{2,7}\right]$
$\left[\mathrm{A}_{1,7,7}, \ldots, \mathrm{A}_{1,13,13}\right]=\left[\phi_{\mathrm{k} 1}, \phi_{\mathrm{\tau} 1}, \phi_{\mathrm{pi}, 1}, \phi_{\mathrm{pr}, 1}, \phi_{\mathrm{p} \ell, 1}, \phi_{\mathrm{pm}, 1}, \phi_{\mathrm{d} 1}\right]$
$\left[\mathrm{A}_{2,5,7}, \ldots, \mathrm{A}_{2,5,13}\right]=\left[\mathrm{K}_{1,8}, \ldots, \mathrm{K}_{1,14}\right]$
$\left[A_{2,6,7}, \ldots, A_{2,6,13}\right]=\left[K_{2,8}, \ldots, K_{2,14}\right]$
$\left[A_{2,7,7}, \ldots, A_{2,13,13}\right]=\left[\odot, \Theta, \phi_{p i, 2}, \phi_{\mathrm{pr}, 2}, \phi_{\mathrm{p} \ell, 2}, \phi_{\mathrm{pm}, 2}, \phi_{\mathrm{d} 2}\right]$. 


\section{REFERENCES}

Adams, J.D. (1990), "Fundamental Stocks of Knowledge and Productivity Growth," Journal of Political Economy 98: 673-702.

Anderson, B.D.O. and J.B. Moore (1979), Optimal Filtering, Englewood Cliffs, NJ: Prentice Hall.

Bureau of Labor Statistics (1997), BLS Handbook of Methods, Washington, DC: Government Printing office.

Burmeister, E. and K.D. Wall (1982), "Kalman-Filtering Estimation of Unobserved Rational Expectations with an Application to the German Hyperinflation," Journal of Econometrics 20: 255-284.

Caballero, R.J. (1999), "Aggregate Investment," pp. 813-862 in Handbook of Macroeconomics, J.B. Taylor and M. Woodford (eds.), Amsterdam, The Netherlands: Elsevier.

Christensen, L.R., D.W. Jorgenson, and L.J. Lau (1971), "Conjugate Duality and the Transcendental Logarithmic Production Function," Econometrica 39: 255-256.

Christensen, L.R., D.W. Jorgenson, and L.J. Lau (1973), "Transcendental Logarithmic Production Frontiers," Review of Economics and Statistics 55: 2845 .

Diewert, W.E. (1971), "An Application of the Shepard Duality Theorem: A Generalized Leontief Production Function," Journal of Political Economy 79: 481-507.

French, M.W. (2000), "Estimating Changes in Trend Growth of Total Factor Productivity: Kalman and H-P Filters versus a Markov Switching Framework," Working Paper, Division of Research and Statistics, Federal Reserve Board, Washington, DC.

Gordon, R.J. (2000), "Does the 'New Economy' Measure up to the Great Inventions of the Past?" Journal of Economic Perspectives 14 (Fall): 49-74.

Griliches, Z. (1995), "R\&D and Productivity: Econometric Results and Measurement Issues," pp. 52-89 in Handbook of the Economics of Innovations and Technological Change, P. Stoneman (ed.), Cambridge, MA: Blackwell.

Hall, R.E. (1973), "The Specification of Technology with Several Kinds of Output," Journal of Political Economy 81: 878-892.

Hamilton, J.D. (1985), "Uncovering Financial Market Expectations of Inflation," Journal of Political Economy 93: 1224-1241.

Hercowitz, Z. (1998), "The Embodiment Controversy: A Review Essay," Journal of Monetary Economics 41: 217-224.

Jorgenson, D.W. (1963), "Capital Theory and Investment Behavior," American Economic Review 53: 247-259.

Jorgenson, D.W. (1966a), "Rational Distributed Lag Functions," Econometrica 32: 135-149. 
Jorgenson, D.W. (1966b), "The Embodiment Hypothesis," Journal of Political Economy 74: 1-17.

Jorgenson, D.W., F.M. Gollop, and B.M. Fraumeni (1987), Productivity and U.S. Economic Growth, Cambridge, MA: Harvard University Press.

Jorgenson, D.W. and J.A. Stephenson (1967), "The Time Structure of Investment Behavior in United States Manufacturing, 1947-1960," Review of Economics and Statistics 49: 16-27.

Kwakernaak, H. and R. Sivan (1972), Linear optimal Control Systems, New York, NY: Wiley-Interscience.

Kydland, F.E. and E.C. Prescott (1982), "Time to Build and Aggregate Fluctuations," Econometrica 50: 1345-1370.

Laub, A.J. (1979), "A Schur Method for Solving Algebraic Riccati Equations," IEEE Transactions on Automatic Control 24: 913-921.

Levy, D. and H. Chen (1994), Estimates of the Aggregate Quarterly Capital Stock for the Post-War U.S. Economy," Review of Income and Wealth 40: 317-349.

Levy, D. (2000), "Investment-Saving Comovement and Capital Mobility: Evidence from Century Long U.S. Time Series," Review of Economic Dynamics 3: 100-136.

Lucas, R.E., Jr. (1967), "Tests of a Capital-Theoretic Model of Technological Change," Review of Economic Studies 34: 175-189.

Lucas, R.E., Jr. and E.C. Prescott (1971), "Investment Under Uncertainty," Econometrica 39: 659-681.

More', J.J., B.S. Garbow, and K.E. Hillstrom (1980), "User Guide for MINPACK1," Report ANL-80-74, Argonne National Laboratory, Argonne, IL.

Nadiri, M.I. and I.R. Prucha (1999), "Dynamic Factor Demand Models and Productivity Analysis," forthcoming in New Directions in Productivity Analysis, E. Dean, M. Harper, and C. Hulten (eds.), Chicago, IL: University of Chicago Press.

National Science Foundation (1998), National Patterns of R\&D Resources: 1998, Special Report, Division of Science Resources $\overline{\text { Studies, }} \overline{\text { Arlington, VA; posted on }}$ internet site http://WWW.nsf.gov/sbe/srs/nprdr/start.htm.

Oliner, S.D. and D.E. Sichel (2000), "The Resurgence of Growth in the Late 1990s: Is Information Technology the Story?" Journal of Economic Perspectives 14 (Fall): 3-22.

Romer, C.D. (1989), "The Prewar Business Cycle Reconsidered: New Estimates of Gross National Product, 1869-1908," Journal of Political Economy 97: 1-37.

Sims, C.A. (1980), "Macroeconomics and Reality," Econometrica 48: 1-48.

Sims, C.A. (1986), "Are Forecasting Models Usable for Policy Analysis?" Federal Reserve Bank of Minneapolis Quarterly Review 70: 250-257. 
Slade, M.E. (1989), "Modeling Stochastic and Cyclical Components of Technical Change: An Application of the Kalman Filter," Journal of Econometrics 41: 363381.

Solow, R. (1957), "Technical Change and the Aggregate Production Function," Review of Economics and Statistics 39: 312-320.

Stiroh, K.J. (2001), "What Drives Productivity Growth?" Federal Reserve Bank of New York Economic Policy Review 7: 37-59.

Zadrozny, P.A. (1988), "Gaussian Likelihood of Continuous-Time ARMAX Models when Data are Stocks and Flows at Different Frequencies," Econometric Theory 4: 109-124.

Zadrozny, P.A. (1990), "Estimating a Multivariate ARMA Model with MixedFrequency Data: An Application to Forecasting U.S. GNP at Monthly Intervals," Working Paper No. 9๑-6, Research Department, Federal Reserve Bank of Atlanta.

Zadrozny, P.A. (1996), "A Continuous-Time Method for Modelling Optimal Investment Subject to Adjustment Costs and Gestation Lags," pp. 231-260 in Dynamic Disequilibrium Modeling, W. Barnett, G. Gandolfo, and C. Hillinger (eds.), Cambridge, UK: Cambridge University Press.

Zadrozny, P.A. (1997), "An Econometric Analysis of Polish Inflation Dynamics with Learning about Rational Expectations," Economics of Planning 30: 221-238. 


\section{CESifo Working Paper Series}

(for full list see www.cesifo-group.de)

1461 Steffen Huck, Kai A. Konrad and Wieland Müller, Merger without Cost Advantages, May 2005

1462 Louis Eeckhoudt and Harris Schlesinger, Putting Risk in its Proper Place, May 2005

1463 Hui Huang, John Whalley and Shunming Zhang, Trade Liberalization in a Joint Spatial Inter-Temporal Trade Model, May 2005

1464 Mikael Priks, Optimal Rent Extraction in Pre-Industrial England and France - Default Risk and Monitoring Costs, May 2005

1465 François Ortalo-Magné and Sven Rady, Heterogeneity within Communities: A Stochastic Model with Tenure Choice, May 2005

1466 Jukka Pirttilä and Sanna Tenhunen, Pawns and Queens Revisited: Public Provision of Private Goods when Individuals make Mistakes, May 2005

1467 Ernst Fehr, Susanne Kremhelmer and Klaus M. Schmidt, Fairness and the Optimal Allocation of Ownership Rights, May 2005

1468 Bruno S. Frey, Knight Fever - Towards an Economics of Awards, May 2005

1469 Torberg Falch and Marte Rønning, The Influence of Student Achievement on Teacher Turnover, May 2005

1470 John Komlos and Peter Salamon, The Poverty of Growth with Interdependent Utility Functions, May 2005

1471 Hui Huang, Yi Wang, Yiming Wang, John Whalley and Shunming Zhang, A Trade Model with an Optimal Exchange Rate Motivated by Current Discussion of a Chinese Renminbi Float, May 2005

1472 Helge Holden, Lars Holden and Steinar Holden, Contract Adjustment under Uncertainty, May 2005

1473 Kai A. Konrad, Silent Interests and All-Pay Auctions, May 2005

1474 Ingo Vogelsang, Electricity Transmission Pricing and Performance-Based Regulation, May 2005

1475 Spiros Bougheas and Raymond Riezman, Trade and the Distribution of Human Capital, June 2005 
1476 Vesa Kanniainen, Seppo Kari and Jouko Ylä-Liedenpohja, The Start-Up and Growth Stages in Enterprise Formation: The "New View" of Dividend Taxation Reconsidered, June 2005

1477 M. Hashem Pesaran, L. Vanessa Smith and Ron P. Smith, What if the UK had Joined the Euro in 1999? An Empirical Evaluation Using a Global VAR, June 2005

1478 Chang Woon Nam and Doina Maria Radulescu, Effects of Corporate Tax Reforms on SMEs' Investment Decisions under the Particular Consideration of Inflation, June 2005

1479 Panos Hatzipanayotou, Sajal Lahiri and Michael S. Michael, Globalization, CrossBorder Pollution and Welfare, June 2005

1480 John Whalley, Pitfalls in the Use of Ad valorem Equivalent Representations of the Trade Impacts of Domestic Policies, June 2005

1481 Edward B. Barbier and Michael Rauscher, Trade and Development in a Labor Surplus Economy, June 2005

1482 Harrie A. A. Verbon and Cees A. Withagen, Tradable Emission Permits in a Federal System, June 2005

1483 Hendrik Hakenes and Andreas Irmen, On the Long-Run Evolution of Technological Knowledge, June 2005

1484 Nicolas Schmitt and Antoine Soubeyran, A Simple Model of Brain Circulation, June 2005

1485 Carsten Hefeker, Uncertainty, Wage Setting and Decision Making in a Monetary Union, June 2005

1486 Ondřej Schneider and Jan Zápal, Fiscal Policy in New EU Member States - Go East, Prudent Man!, June 2005

1487 Christian Schultz, Virtual Capacity and Competition, June 2005

1488 Yvan Lengwiler and Elmar Wolfstetter, Bid Rigging - An Analysis of Corruption in Auctions, June 2005

1489 Johannes Becker and Clemens Fuest, Does Germany Collect Revenue from Taxing Capital Income?, June 2005

1490 Axel Dreher and Panu Poutvaara, Student Flows and Migration: An Empirical Analysis, June 2005

1491 Bernd Huber and Marco Runkel, Interregional Redistribution and Budget Institutions under Asymmetric Information, June 2005

1492 Guido Tabellini, Culture and Institutions: Economic Development in the Regions of Europe, July 2005 
1493 Kurt R. Brekke and Michael Kuhn, Direct to Consumer Advertising in Pharmaceutical Markets, July 2005

1494 Martín Gonzalez-Eiras and Dirk Niepelt, Sustaining Social Security, July 2005

1495 Alfons J. Weichenrieder, (Why) Do we need Corporate Taxation?, July 2005

1496 Paolo M. Panteghini, S-Based Taxation under Default Risk, July 2005

1497 Panos Hatzipanayotou and Michael S. Michael, Migration, Tied Foreign Aid and the Welfare State, July 2005

1498 Agata Antkiewicz and John Whalley, BRICSAM and the Non-WTO, July 2005

1499 Petr Hedbávný, Ondřej Schneider and Jan Zápal, A Fiscal Rule that has Teeth: A Suggestion for a 'Fiscal Sustainability Council' underpinned by the Financial Markets, July 2005

1500 J. Atsu Amegashie and Marco Runkel, Sabotaging Potential Rivals, July 2005

1501 Heikki Oksanen, Actuarial Neutrality across Generations Applied to Public Pensions under Population Ageing: Effects on Government Finances and National Saving, July 2005

1502 Xenia Matschke, Costly Revenue-Raising and the Case for Favoring Import-Competing Industries, July 2005

1503 Horst Raff and Nicolas Schmitt, Why Parallel Trade may Raise Producers Profits, July 2005

1504 Alberto Bisin and Piero Gottardi, Efficient Competitive Equilibria with Adverse Selection, July 2005

1505 Peter A. Zadrozny, Necessary and Sufficient Restrictions for Existence of a Unique Fourth Moment of a Univariate GARCH(p,q) Process, July 2005

1506 Rainer Niemann and Corinna Treisch, Group Taxation, Asymmetric Taxation and Cross-Border Investment Incentives in Austria, July 2005

1507 Thomas Christiaans, Thomas Eichner and Ruediger Pethig, Optimal Pest Control in Agriculture, July 2005

1508 Biswa N. Bhattacharyay and Prabir De, Promotion of Trade and Investments between China and India: The Case of Southwest China and East and Northeast India, July 2005

1509 Jean Hindriks and Ben Lockwood, Decentralization and Electoral Accountability: Incentives, Separation, and Voter Welfare, July 2005

1510 Michelle R. Garfinkel, Stergios Skaperdas and Constantinos Syropoulos, Globalization and Domestic Conflict, July 2005 
1511 Jesús Crespo-Cuaresma, Balázs Égert and Ronald MacDonald, Non-Linear Exchange Rate Dynamics in Target Zones: A Bumpy Road towards a Honeymoon - Some Evidence from the ERM, ERM2 and Selected New EU Member States, July 2005

1512 David S. Evans and Michael Salinger, Curing Sinus Headaches and Tying Law: An Empirical Analysis of Bundling Decongestants and Pain Relievers, August 2005

1513 Christian Keuschnigg and Martin D. Dietz, A Growth Oriented Dual Income Tax, July 2005

1514 Fahad Khalil, David Martimort and Bruno Parigi, Monitoring a Common Agent: Implications for Financial Contracting, August 2005

1515 Volker Grossmann and Panu Poutvaara, Pareto-Improving Bequest Taxation, August 2005

1516 Lars P. Feld and Emmanuelle Reulier, Strategic Tax Competition in Switzerland: Evidence from a Panel of the Swiss Cantons, August 2005

1517 Kira Boerner and Silke Uebelmesser, Migration and the Welfare State: The Economic Power of the Non-Voter?, August 2005

1518 Gabriela Schütz, Heinrich W. Ursprung and Ludger Wößmann, Education Policy and Equality of Opportunity, August 2005

1519 David S. Evans and Michael A. Salinger, Curing Sinus Headaches and Tying Law: An Empirical Analysis of Bundling Decongestants and Pain Relievers, August 2005

1520 Michel Beine, Paul De Grauwe and Marianna Grimaldi, The Impact of FX Central Bank Intervention in a Noise Trading Framework, August 2005

1521 Volker Meier and Matthias Wrede, Pension, Fertility, and Education, August 2005

1522 Saku Aura and Thomas Davidoff, Optimal Commodity Taxation when Land and Structures must be Taxed at the Same Rate, August 2005

1523 Andreas Haufler and Søren Bo Nielsen, Merger Policy to Promote 'Global Players'? A Simple Model, August 2005

1524 Frederick van der Ploeg, The Making of Cultural Policy: A European Perspective, August 2005

1525 Alexander Kemnitz, Can Immigrant Employment Alleviate the Demographic Burden? The Role of Union Centralization, August 2005

1526 Baoline Chen and Peter A. Zadrozny, Estimated U.S. Manufacturing Production Capital and Technology Based on an Estimated Dynamic Economic Model, August 2005 